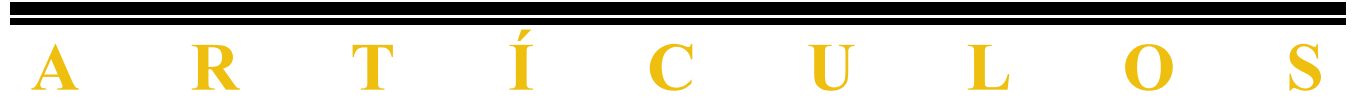




\section{UNA FUNDAMENTACIÓN DE LA SOCIOLOGÍA DEL DERECHO ${ }^{1}$}

I

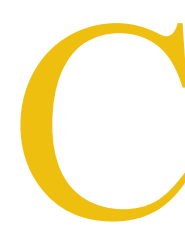

uando uno de los líderes y fundadores de la que últimamente viene denominándose ciencia del derecho «sociológica» publica una gran obra cuyo título anuncia la fundamentación de esta nueva ciencia, existen motivos para aproximarse a dicha obra con gran expectación, puesto que lo que se echa en falta en los numerosos intentos de reformar la ciencia del derecho, en los numerosos ataques que bajo la bandera de la «sociología» se han dirigido contra una jurisprudencia atrasada y acientífica, es precisamente un fundamento científico. Esta carencia es tal que habría que cuestionar seriamente si bajo el lema común de la «Sociología» se presenta una aspiración por realizar un objetivo claro y determinado. Si ha habido alguien llamado o especialmente capacitado para desarrollar el fundamento científico mencionado, esa persona es desde luego Eugen Ehrlich, cuyos agudos escritos fascinantes por su vivaz retórica han generado desde hace más de veinte años un importante grupo de seguidores.

La oposición fundamental, en lo que se refiere a objeto y método, que amenaza con dividir la ciencia del derecho en dos direcciones completamente distintas, resulta del doble modo de consideración (Betrachtungsweise) al que se cree poder someter el fenómeno jurídico. Se puede considerar (betrachten) el derecho como norma, es decir, como una forma determinada de deber-ser en tanto que regla específica de deber-ser y, en consecuencia, constituir $^{2}$ la ciencia del derecho como una ciencia valorativa,

${ }^{1}$ Este artículo de Kelsen apareció en la revista Archiv für Sozialwissenschaft und Sozialpolitik en 1915 y constituye una crítica al libro de E. Ehrlich Fundamentación de la sociología del derecho (München und Leipzig, Dunker U. Humboldt, 1913).

${ }^{2}$ El deber-ser jurídico aparece junto al deber-ético, al deber-ser estético y al deber-ser gramatical, como una de las diferentes posibilidades del deber-ser. El 
normativa y deductiva, como la ética o la lógica. También se puede intentar, sin embargo, concebir el derecho como una parte de la realidad social, como un hecho o proceso cuya regularidad puede ser aprehendida inductivamente y explicada causalmente. El derecho es aquí una regla de ser (Seinsregel) referida a un determinado comportamiento humano, mientras que la ciencia del derecho es una ciencia de la realidad (Wirklichkeitswisserischft) que funciona según el patrón de las ciencias naturales. Con ello no se discute, desde luego, hasta qué punto dicha ciencia también es, como tal, una ciencia social.

Sólo en la medida en que se atribuye el carácter de social a una regla que expresa un determinado comportamiento similar de los hombres en su convivencia, se puede caracterizar como ciencia social o, si se quiere, como sociología, una ciencia que se preocupa de determinar las reglas de la vida jurídica o las reglas jurídicas. Que una sociología así caracterizada sea teóricamente posible, así como deseable para la explicación de la convivencia humana, no se va a poner en duda. Más tarde discutiremos en qué medida es posible una sociología del derecho. En todo caso es necesario dejar claro que una sociología del derecho es esencialmente diferente, tanto en lo que se refiere al objeto como al método, de una ciencia del derecho que tiene como tarea conocer no lo que de hecho es sino lo que debe ser con arreglo al derecho, esto es una ciencia valorativa y no explicativa, en otras palabras, una ciencia del derecho normativa. Naturalmente, no se puede hablar de una lucha entre ambas disciplinas en el sentido de que sólo una de ellas sea posible y esté justificada desde el punto de vista general del conocimiento científico ${ }^{3}$. Se apunta simplemente que es inad-

valor jurídico ha de ser pensado, por tanto, no como valor absoluto sino como valor relativo. El concepto de deber-ser ha de ser considerado en un sentido puramente formal, sobre todo en oposición a la concepción imperante que considera el «deber-ser» en el sentido material de un valor absoluto. El conocimiento del deber-ser jurídico, y no su establecimiento (Statuirung) corresponde a la ciencia jurídica; en este sentido, la ciencia jurídica es de carácter normativo. Compárese con Kelsen, Hans, «Hauptprobleme der Staatsrechtlehre», Ubingen, 1911, pp. 3 y ss.

${ }^{3}$ Recientemente Radbruch (Grundzüge der Rechtsphilosophie», Leipzig, 1914) ha intentado -a partir del sistema científico de Rickert- asignar al concepto de derecho su puesto entre las categorías del ser y del deber-ser. Este «singular reino intermedio» (p. 38) es el reino de la cultura; el concepto de derecho es un concepto cultural, la ciencia jurídica una ciencia cultural. No es éste el lugar apropiado para discutir estas cuestiones. La imposibilidad lógica de esta concepción aparece ya en los pasajes introductorios de la obra en cuestión: «el fenómeno cultural es una «formación del ser» (Seinsgebilde) en la medida en que puede ser el objeto de un juicio (es decir, de una valoración), en la medida en que constituye el substrato posible de un valor o de un disvalor» (p. 39). Y por 
misible que se produzca una confusión en la manera de plantear los problemas que tiene cada dirección, o en otras palabras, que hay que evitar el sincretismo de los métodos de la ciencia del derecho normativa y de la sociología del derecho explicativa ${ }^{4}$.

Bajo tales circunstancias, nos preguntamos si tiene todavía algún sentido caracterizar como ciencia del derecho a ambas direcciones de conocimiento científico, caracterización que despierta la ilusión de un objeto común. En efecto, la diferencia en el modo de consideración (Betrachtungsrichtung) y en la forma de pensamiento (Denkform) -aquí ser, allá debe-ser- trae como consecuencia una diversidad completa del objeto. Lo que los hombres deben hacer con arreglo a derecho y lo que los hombres hacen regularmente en cualquier tipo de relación, deben ser dos cosas al menos formalmente diferentes en el caso de que el contenido de la norma que determina lo que debe suceder y el contenido de la regla que expresa lo que de hecho sucede coinciden, esto es, en el supuesto de que sólo existiera un derecho consuetudinario. Desde un punto de vista puramente metodológico, no cabe duda de que tanto la forma de conocimiento cuyo paradigma viene establecido por la jurisprudencia normativa, como los juicios sobre derechos y obligaciones y sobre normas jurídicas en el sentido de normas y relaciones de deber-ser, son completamente ajenos a una sociología

ello, para Radbruch el derecho también es una «formación» de ser «en la medida en que sirve de substrato al valor de justicia» $(p, 39)$. Tras haberse referido a las categorías de ser y de deber-ser como una «división fundamental de todo lo pensable» (para las que naturaleza-realidad y valor-fin son sinónimos) ¿cómo puede Radbruch afirmar que una formación de ser se convierte en el substrato de un valor si líneas arriba ha mantenido (p. 35) -correctamente- que lo «dado» se transforma en el reino del ser cuando uno se enfrenta a ello «con una actitud ciega ante los valores (wertblind), sin preocuparse del valor o disvalor; mientras que si lo «dado» es representado de un modo valorativo, se ordena hacia el reino del deber-ser, hacia el reino de los valores, etc.». El derecho o un fenómeno cultural sólo pueden por tanto constituir una formación de ser en la medida en que el modo de consideración (Betrachtung) es «ciego ante los valores». ¡Sin embargo el derecho como fenómeno cultural según Radbruch es precisamente el objeto de una valoración o el substrato de un valor! Aquí queda planteada una contradicción lógica. Un ente (Seiendes) no puede ser valorado, dado que algo es representado como algo-que-es (seiend) sólo de acuerdo con un modo de consideración (Betrachtungsrichtung) que es esencialmente distinto del que conduce a una valoración. La contradicción desaparece al exponer las categorías de ser y de deber-ser como una «división fundamental de todo lo pensable» (lo que hace el propio Radbruch), como una división exhaustiva entre dos conceptos autoexcluyentes; de ahí que una cosa que ni es ni debe-ser, ni ambas cosas a la vez, no pueda ser pensable.

4 Compárase con: Kelsen, Hans, «Zur Sociologie des Rechtes» en Archiv für Sozialwissenschaft und Soziapolitik, Vol. XXXIV, p. 601 y ss. 
del derecho que sólo se ocupa del ser. Una ciencia del derecho «sociológica» nunca podría expresar a qué y bajo qué condiciones está obligada jurídicamente o tiene derecho una persona o un grupo de personas, sino meramente lo que, bajo ciertas condiciones, determinados hombres (ipuesto que el concepto de persona es puramente normativo!), hacen o dejan de hacer habitualmente. Todos los conocimientos de una ciencia del derecho sociológica, sólo pueden ser conocimientos sobre la realidad, juicios de hecho, es decir, juicios sobre el nexo causal de determinados procesos regulares, y no juicios de valor como por ejemplo «esto es lícito, esto es ilícito», «alguien está obligado a esto, alguien tiene derecho a esto otro», del mismo modo que para la biología, la química o la psicología, no existe ni el bien ni el mal, ni lo lícito ni lo ilícito, ni el derecho ni la obligación, sino meramente hechos -indiferentes desde un punto de vista valorativo- y sus conexiones causales.

No vamos a tratar aquí la cuestión de saber si y cómo una parte de la realidad social se puede diferenciar como derecho o como vida jurídica frente a otra forma de realidad social para alguien que adopte un modo de consideración (Betrachtung) puramente causal -esto es, incondicionado (voraussetzungslose)-, que no guarde relación con ciertas normas (reglas de deber-ser) consideradas como válidas por el observador (Betrachter). En otras palabras, no se plantea la cuestión de saber si y cómo podría realizarse el postulado que dice que el derecho es aprehendido como una forma específica de una regla de ser de la convivencia humana que debe ser distinguida de otras reglas sociales de comportamiento. La solución a este problema constituye, evidentemente, la clave para una teoría sociológica del derecho. Quede aquí solamente apuntado lo que viene a continuación. Supongamos que la solución a dicho problema se revelara teóricamente imposible y que, asimismo, se reconociera como esencial del conocimiento jurídico, como lo específico de los enunciados que expresan algo lícito el que éstos sean una declaración sobre un deber-ser, sobre una norma, sobre una obligación o sobre un derecho, es decir, un juicio de valor (puesto que un análisis de todos los enunciados jurídicos afectaría al elemento valorativo o de deber-ser). En este caso, constituiría un grave error caracterizar de la misma forma, es decir, como ciencia del derecho, a la jurisprudencia normativa y a la disciplina sociológica en cuestión. Con lo que desde luego no se está cuestionando en modo alguno el hecho de que pueda existir, junto a una ciencia del derecho normativa, otra ciencia que explique e investigue desde otra dirección el comportamiento social habitual de los hombres.

Incluso en el caso de que se consiguiera diferenciar ciertas 
reglas del comportamiento como «derecho» frente a otras reglas sociales, de manera que se diera un fundamento a una sociología del derecho particular, ese concepto de derecho -que representaría una categoría del ser social- sería, como es obvio, algo esencialmente distinto del concepto normativo de derecho que aprehende el derecho como norma -considerada como una categoría del deber-ser. Una cuestión diferente sería la de determinar si entre ambos conceptos existe algún tipo de relación que justifique una caracterización similar.

La incapacidad para discernir claramente desde el principio entre el modo de consideración del valor y el modo de consideración de la realidad (Wert- und Wirklichkeitsbetrachtung) debe ser percibida como una carencia grave en el trabajo de Ehrlich. Este autor dice querer establecer la sociología del derecho como una ciencia pura «teórica» frente a la hasta ahora jurisprudencia «práctica». Ehrlich reprocha a la equivocada jurisprudencia el hecho de ser «abstrayentemente deductiva» («abstrahierend deduktiv»). «Como si para el espíritu humano no hubiera mayor logro que la creación de formas vacías (blutleere Gebilde) que cuanto más abstractas son, pierden más el contacto con la realidad. [Dicha ciencia] se sitúa de esta manera en aguda contradicción con las ciencias auténticas, en las que domina el método inductivo y que intentan profundizar nuestra penetración en la esencia de las cosas a través de las observaciones de hechos y de la acumulación de experiencias» (p. 6). Ehrlich sostiene, evidentemente, la opinión que afirma que las ciencias sólo pueden ser inductivas al tiempo que da la impresión de ignorar la posibilidad de un conocimiento científico a través del método deductivo. También parece ignorar, con su aversión hacia las abstracciones «vacías», que ningún conocimiento puede renunciar a las abstracciones o a los conceptos, los cuales deben ser necesariamente «vacíos» (blutleer) frente a los concretos fenómenos individuales. Por otra parte, no se puede reprochar la falta de «contacto con la realidad» a una ciencia que desde un principio nunca ha pretendido ser una explicación de la realidad. Lo que se desprende de la posición de Ehrlich es la idea de que una «ciencia» del derecho sólo es posible como disciplina inductiva y causal-explicativa. Una sociología del derecho debería concebirse, sin duda alguna, de esta forma, situándose en completa oposición a una jurisprudencia normativa. Sólo que Ehrlich establece la oposición entre su sociología del derecho y la jurisprudencia contemporánea siguiendo una dirección completamente distinta. Dicha ciencia del derecho considera (betrachtet) el derecho, erróneamente, como «una regla para la actuación de los tribunales y de las otras autoridades (estatales)», mientras que la sociología 
del derecho concibe el derecho «como una regla de la acción humana general» (des allgemeinen menschlichen Handeln) (p. 9), y de esta forma, el auténtico «concepto científico de derecho» está en la base de su conocimiento (p. 6). Dado el doble significado de la expresión "regla" -regla de ser o de deber-ser-, todo lo que se acaba de apuntar depende del sentido en el que Ehrlich emplee dicha expresión. En nuestra opinión Ehrlich confunde completamente ambos significados al presuponer que una regla del actuar es «obviamente una regla según la cual no sólo se actúa, sino también según la cual se debe actuar» (p. 7). ¡Este enunciado es evidentemente falso! Una regla que ha sido obtenida a partir de un modo de consideración (Betrachtung) causal-explicativo no es más que una regla de ser incapaz de dar una indicación acerca de lo que debe-ser. Lo que debe suceder no es, evidentemente, una cuestión que atañe al modo de consideración (Betrachtung) causal-explicativa. El biólogo no intenta determinar cómo deben comportarse determinadas formas de vida bajo determinadas circunstancias, o cuáles son sus obligaciones y sus derechos, sino exclusivamente cómo se comportan regularmente. De la misma forma, sólo así la sociología puede -en la medida en que la sociología es una ciencia del ser causal-explicativadeterminar las reglas de ser del comportamiento humano; y estas reglas de actuar ofrecen tan poca información sobre el deber-ser como las reglas o las leyes de la biología. ¡Es un modo de consideración (Betrachtungsweise) completamente distinto, que está orientado hacia las reglas del deber-ser, es decir, hacia las normas! Pueden existir desde luego normas que prescriban como debido (gesollt) un comportamiento que ha existido regularmente desde tiempos inmemoriales, como es el caso, por ejemplo, de una norma que prescribiera que se debe actuar de la misma forma que lo han venido haciendo nuestros antepasados desde tiempos inmemoriales. Este tipo de reglas de deber-ser no explicaría nada, no mostraría ningún nexo causal. Ahora bien, esta norma no es la única norma posible y constituiría un claro error mantener la opinión contraria. Pueden existir normas jurídicas que tengan dicho contenido. ¡Pero también existen, sin duda, otras normas jurídicas! De esta forma, en el campo del derecho, las reglas-de-ser y de deber-ser son completamente distintas según la forma, mientras que según el contenido pueden coincidir en parte, bien que esa parte sea hoy en día mínima. ¿Podría Ehrlich seriamente mantener la opinión de que incluso hoy el derecho consuetudinario es el único válido?

Si se examina más de cerca la oposición en la que sitúa Ehrlich su nueva sociología del derecho «teórica» frente a la jurisprudencia «práctica» contemporánea, se puede apreciar que dicha oposición 
no tiene en modo alguno un significado fundamental y que no puede ser caracterizada como tal oposición. Hasta ahora se ha intentado determinar las reglas con arreglo a las cuales actúa una determinada categoría de hombres: los jueces y otros órganos estatales. La sociología del derecho se ocupa, sin embargo, de las reglas con arreglo a las cuales actúan todos los hombres. En ambos casos Ehrlich identifica las reglas del actuar efectivo con las del actuar debido (Handelnsollen). Se debería pensar entonces que hasta ahora la jurisprudencia habría sido también una sociología, si bien no una sociología general sino especial, una sociología de los órganos del estado -en el caso de que el estado sea identificado con sus órganos-: una sociología del estado. Pero lo que hace falta urgentemente es una sociología del derecho que presente las reglas de la acción humana «general». Es obvio que esta acción humana «general» no puede ser la acción de los hombres en general, sino sólo una acción especial de los hombres, una acción con arreglo a una determinada dirección, puesto que no es una sociología general sino una sociología del derecho la que debe ser fundada. Más adelante se tratará la manera en que Ehrlich diferencia en tanto que «derecho» aquella determinada dirección frente a las restantes direcciones de la acción humana.

«Acción humana general» (allgemeines menschliches Handeln) debe ser evidentemente la expresión -muy incorrecta- que se utiliza para designar algo más que el mero actuar de los órganos del estado. Bastante incomprensible es, sin embargo, que Ehrlich crea ofrecernos, con esta extensión de su investigación acerca de los órganos del estado, un modo de consideración (Betrachturig) científico (teórico) en oposición al práctico que está «hecho a la medida de los funcionarios judiciales». ¡Parece como si Ehrlich identificara la oposición entre la regla para la acción de los órganos estatales y la regla para la acción de todos los hombres con la oposición entre teórico (científico) y práctico, es decir, con la oposición entre causal y normativo, entre ser y deber-ser! Si fuera correcto afirmar que la jurisprudencia dominante se ocupa de las reglas con arreglo a las cuales actúan los órganos del Estado (y, en consecuencia, con arreglo a las cuales deben actuar, en el sentido de Ehrlich), entonces sería igualmente correcto afirmar que una disciplina teórica y científica, como la sociología del derecho de Ehrlich, determina las reglas con arreglo a las cuales actúan no sólo los tribunales, sino también todos los hombres, sobre todo si se considera que estas «reglas de la acción humana general» son no sólo reglas de ser sino también y al mismo tiempo reglas de deber-ser, es decir, normas. Estas «reglas» también reciben el nombre de «ordenamiento» (Ordnung), el cual 
«asigna a cada miembro de la comunidad (Genossenschaft) sus tareas y su puesto, su posición de subordinación o su posición de superioridad en la sociedad» (p. 18). Estas reglas se deben concebir, por tanto, como reglas de deber-ser; y lo que es más, se dice que en este ordenamiento se cumplen obligaciones jurídicas. ¡Estas reglas, cuya determinación es la tarea de la ciencia del derecho «científica» (por oposición a la jurisprudencia «práctica»), cuya obtención es el objetivo de la sociología del derecho «teórica», tienen, simultáneamente en consecuencia, un carácter teórico y práctico!

¡Así comienza la «fundamentación» de una nueva ciencia!

II

No es fácil escribir una crítica sistemática de una obra que, como la Fundamentación de la Sociología del Derecho de Ehrlich, es completamente asistemática y tiene más bien el carácter de recopilación de algunos ensayos. Con ello no quiere decirse que el sistema sea siempre una virtud. La ausencia de una estructura o articulación rígidas -especialmente en trabajos que contienen una crítica negativa- es un aligeramiento que agradecen los lectores. Ahora bien, en la fundamentación de una nueva ciencia no se puede apenas renunciar a una construcción planeada y menos aún a una fundación (Fundierung) de los conceptos más importantes y de los principios, sin que la cuestión del fundamento deje de ser pertinente. Desgraciadamente, el trabajo de Ehrlich deja mucho que desear en este sentido. Es casi imposible seguir a lo largo de la obra la concepción de Ehrlich propiamente dicha, puesto que ésta adolece de toda conexión interna con cada una de las partes en donde se repite. Además, hay importantes presuposiciones (Voraussetzungen) que sólo se discuten en medio de cuestiones particulares interrumpidas a su vez por largos excursos histórico-jurídicos que no tienen nada que ver con el tema tratado.

Son analizados a continuación los conceptos fundamentales y los problemas capitales con los que opera la concepción ehrlichiana, todo ello en conexión con la idea que tiene Ehrlich de la sociología del derecho como una ciencia que debe obtener las reglas de la acción humana general a través del método inductivo.

Uno de los resultados más importantes a los que llega el trabajo de Ehrlich es ciertamente un conocimiento negativo: el derecho no se compone, como siempre se había creído hasta ahora, de enunciados jurídicos (Rechtssätzen). Ehrlich no deja de protestar con el suficiente énfasis contra la doctrina equivocada 
que mantiene que el derecho es una «totalidad de enunciados jurídicos». Antes de examinar el argumento de Ehrlich debemos establecer lo que se puede entender por «enunciado jurídico» en general.

«Enunciado jurídico» significa o bien la expresión lingüística de un deber-ser jurídico, y en este caso es idéntico a una norma jurídica, o bien la expresión lingüística de una regla del acaecer efectivo, y en este caso se trata de un sinónimo de regla de derecho en el sentido del ser (Rechtsregel im Seinssinne). Una diferenciación entre «proposición jurídica» (Rechtssatz) y «norma jurídica» (Rechtsnorm) no es aconsejable, aunque en ocasiones dicha diferenciación tiene lugar, por ejemplo, cuando se entiende como «norma jurídica» sólo el imperativo del comportamiento con arreglo al derecho, mientras que con el término «enunciado jurídico» se designa otra forma lingüística, por ejemplo, el juicio que conecta una consecuencia ilícita con un determinado supuesto de hecho (Tatbestand). La norma jurídica viene en este caso decretada por el enunciado jurídico. Para documentar el uso lingüístico general de los términos «enunciado jurídico» y «norma jurídica» sería conveniente, quizá, citar a un autor cuya autoridad reconoce sin reservas el mismo Ehrlich. Gierke dice en «Deutschen Privatrecht» (p. 133): «El derecho objetivo... es la quintaesencia de los enunciados jurídicos. Los enunciados jurídicos son normas que, con arreglo al convencimiento declarado de una sociedad, deben determinar externamente y de forma incondicional la libre voluntad humana». Gierke identifica, por tanto, enunciado jurídico y norma jurídica.

Ehrlich mantiene, sin embargo, que en los primeros tiempos había derecho y relaciones jurídicas pero no enunciados jurídicos. El derecho de las épocas más remotas era idéntico al «orden interno» (innere Ordnung) de las colectividades (Verbände) primitivas. «En los estadios de desarrollo inferiores existe una ausencia completa de enunciados jurídicos generales» (p. 28). Pero, ¿qué es el «orden interno» de las colectividades sociales? Obviamente, lo que todo «orden», es decir, o bien una totalidad de normas, o bien determinadas reglas-de-ser relativas al comportamiento de los miembros de la colectividad, es decir, en última instancia una cierta regularidad en su comportamiento recíproco. Se supone que para la sociología ese significado último del concepto de orden debería ser decisivo (maßgebend). De este «orden interno» de las colectividades primitivas que es el derecho de las mismas de acuerdo con la posición ehrlichiana, dice Ehrlich: «éste determina las condiciones y las consecuencias de un matrimonio válido, las relaciones intramatrimoniales, las relaciones entre los padres y los hijos y las relaciones recíprocas con otros clanes y familias» (p. 
22). ¡Este orden es desde luego cualquier cosa menos una regla-de-ser sociológica! Ehrlich lo describe como disposiciones de deber-ser expresas. ¿Y no se debería considerar qué otra cosa, además de normas o enunciados jurídicos (en verdad enunciados jurídicos generales $\mathrm{y}$ vigentes para todos los miembros de la colectividad) deberían ser estas disposiciones fundantes de relaciones jurídicas que determinan las condiciones de un matrimonio válido o las relaciones entre padres e hijos? ¿No es cada parte constitutiva del «orden interno» (el cual, en palabras de Ehrlich, «determina las condiciones y las consecuencias de un matrimonio válido») un enunciado general del derecho matrimonial, dado que dicha parte constitutiva se refiere no a un matrimonio concreto, sino a todas las uniones que en la colectividad tienen vigencia en tanto que «matrimonio»? En esta colectividad, el hecho concreto de la unión entre dos personas ¿no constituye un matrimonio sólo en la medida en que viene referido (zuspricht) al «orden» de la colectividad, es decir, al ordenamiento matrimonial? Y cada supuesto de hecho ¿no tiene solamente aquellas consecuencias jurídicas que vienen determinadas por el ordenamiento matrimonial? Ehrlich mantiene que en estas colectividades hay un «derecho contractual». «El derecho contractual sólo se ocupa de los contratos que se celebran; no existen en modo alguno enunciados jurídicos generales sobre el contrato, faltan las reglas obligatorias, complementarias e interpretativas que aparecen en el Corpus iuris y en los códigos modernos» (p. 23). ¡Ciertamente! El ordenamiento jurídico del Corpus iuris y del código civil alemán moderno se diferencian en cierta medida del derecho existente «en las épocas remotas de los pueblos». Pero si en dichas épocas remotas, una promesa hecha por A y aceptada por B debía fundar una relación jurídica, debía dar lugar a un contrato con un efecto jurídico, es necesario presuponer la validez de un enunciado jurídico que dispusiera que un concurso de voluntades declarado como el que se contempla debía ser obligatorio. Si no, ¿cómo podría hablarse de derechos y obligaciones? Pero si nos limitamos a la consideración de los hechos, y podemos mantener, sobre la base del material observado, que también en las épocas remotas se formaban vínculos familiares duraderos en el seno de las colectividades, que en aquel tiempo los contratos también eran respetados de hecho, ¿no se está constatando con esto la existencia de una regla-de-ser, de una regla de derecho en el sentido en el que Ehrlich desarrolla el concepto sociológico-científico de derecho? ¿No estamos en presencia de un enunciado jurídico general en el interior de la colectividad, enunciado jurídico general correspondiente a la segunda significación de la expresión regla de derecho en el sentido de una 
regla-de-ser? Debemos renunciar a toda comprensión de la posición de Ehrlich cuando éste afirma -tras haber definido como el único concepto científico de derecho «la regla de la acción humana»- que el antiguo derecho estatal romano fue un derecho sin reglas: «lo que Mominsen nos ofrece bajo ese título es (...) una descripción de lo que los órganos estatales romanos hicieron efectivamente durante la existencia del imperio romano. Mominsen ve por todas partes enunciados jurídicos generales que son en realidad, y salvo en el caso de excepciones irrelevantes, el resultado de su propio trabajo intelectual; son deducidos por él pero nunca fueron en Roma una regla para los supuestos de hecho» (p. 24). O, por ejemplo, cuando afirma: «Tácito da cuenta de las relaciones jurídicas de los antiguos germanos, pero basta una mirada superficial a su texto para ver que éste no contiene ningún enunciado jurídico, sino sólo indicaciones sobre lo que los germanos hacían o permitían hacer» (p. 25). Pero para una ciencia sociológica del derecho que considera que el derecho es una regla del comportamiento efectivo, ¿puede haber otro derecho estatal romano distinto del que describe lo que los órganos estatales romanos han hecho efectivamente, otro derecho alemán diferente del que da cuenta de lo que los germanos han hecho efectivamente? ¿Consiste el derecho en algo distinto de estas regularidades, de estas reglas-de-ser? ¿No constituyen ya estas reglas lo que Ehrlich más tarde denomina derecho «vivo» para designar el objeto propio de la jurisprudencia? ¿Y pueden estas reglas de derecho ser obtenidas a partir de otra cosa que no sea los hechos, son estas reglas sociológicas algo diferente de las reglas biológicas o meteorológicas que tan sólo pueden ser abstraídas a partir de la realidad? ¿Pero es posible que Ehrlich entienda bajo la expresión «enunciado jurídico» una regla de deber-ser? Utilizando una terminología completamente arbitraria, Ehrlich entiende por «enunciado jurídico»: «la regla de derecho fija y formulada a través de palabras que, emanando de un poder ejercido sobre el individuo, se impone a éste externamente» (p. 22). Ehrlich se refiere obviamente a la norma jurídica (en el sentido del deber ser) heterónoma. En otros lugares insiste de nuevo en que: «el enunciado jurídico es la formulación vinculante, general y contingente de una disposición de derecho en una ley, o en un código» (p. 29). Pero, ¿desde cuándo pertenece a la esencia del enunciado jurídico que éste sea establecido por escrito? Tales enunciados jurídicos no existían obviamente en los tiempos más remotos. ¡El ordenamiento jurídico actual tampoco consiste, desde luego, en tales enunciados jurídicos! Pero si Ehrlich entiende bajo la expresión «enunciado jurídico» una norma vinculante general, es decir, una disposición de deber-ser, no se puede ciertamente 
concebir que dicho autor mantenga que el derecho se compone, al menos en parte, de tales enunciados jurídicos. ¡Hay que concluir, por tanto, que el derecho es en parte una regla-de-ser y en parte una disposición de deber-ser! ¡Esto no es en modo alguno posible si debemos ofrecer un concepto unitario de derecho! Parece como si Ehrlich opinara que originariamente no ha existido ningún enunciado jurídico «general» (pp. 23-24), sino tan sólo los diferentes órdenes «internos» individuales de las colectividades. Cada orden, no obstante, y en la medida en que se trataba de un «orden», debía tener una validez general o constituir una regla con eficacia general en la colectividad. Los enunciados jurídicos no tenían más que un ámbito de validez limitado. Sólo con el paso del tiempo se amplían las comunidades de derecho, los círculos jurídicos (Rechtskreise).

Al entender Ehrlich el concepto de enunciado jurídico en el sentido de norma jurídica, de regla de deber-ser, se dirige contra la concepción equivocada de los juristas que mantiene que sólo se puede hablar de relaciones jurídicas o de negocios jurídicos si se presupone la existencia de normas jurídicas o de enunciados jurídicos. «Cuando los juristas sostienen que antes de concluir un acuerdo vinculante o de redactar un testamento vinculante, es necesaria la existencia de un enunciado jurídico según la cual los contratos o los testamentos tienen fuerza vinculante (¡téngase en cuenta el concepto de enunciado jurídico!), están poniendo lo abstracto antes de lo concreto» (p. 28). Los juristas incurren, según Ehrlich, en un error lógico. «El estado existía con anterioridad a la constitución del estado (Staatsverfa $\beta$ ung), la familia es anterior al orden familiar, la posesión precede a la propiedad, los contratos existían antes que el derecho de los contratos, e incluso el testamento, allí donde aparece con carácter originario, es anterior al derecho testamentario» (p. 28). Es realmente difícil defender una confusión tan elemental entre la relación temporal y lógica, como la que aquí sostiene Ehrlich. ¡Nunca un hombre razonable ha sostenido que las normas jurídicas preceden temporalmente a los hechos que son calificados jurídicamente por aquéllas! Sólo lógicamente debe ser presupuesta una norma jurídica en el caso de que un supuesto de hecho deba tener un significado jurídico. ¿O cree realmente Ehrlich que un proceso natural (Seinsvorgang) cualquiera, pongamos por caso una declaración de voluntad acerca de lo que debe suceder con determinados objetos del declarante a su fallecimiento, puede ser considerada con independencia de que dicha declaración deba tener un determinado efecto jurídico? ¿Piensa Ehrlich seriamente que las cualidades «lícito»e «ilícito» obligación y pretensión, se adhieren a los procesos naturales 
como los colores o las temperaturas? ¿Cree que los juicios de valor o de significado (Wertoder Bedeutungsurteile) objetivos, como son los juicios jurídicos, son posibles a partir de una mera consideración (Betrachtung) de la realidad? ¡Carece de sentido decir que los contratos existen «con anterioridad» a la presencia de un enunciado jurídico del derecho de contratos, cuando un «contrato» es un hecho real (reale Seinstatsache) del mundo exterior mientras que el enunciado jurídico del derecho de contratos es una norma, una condición o suposición (eine Betrachtungsvoraussetzung) existente en el pensamiento (im Denken) del que califica ese hecho! No tiene sentido mantener que existen acuerdos «vinculantes», es decir que se puede imaginar un acuerdo vinculante, sin que sea presupuesta una norma que apareje ciertas obligaciones al concurso de voluntades -es decir, que estatuya un deber-ser respecto de las voluntades declaradas. Cuando Ehrlich recuerda desdeñoso a los juristas que «no es de los enunciados jurídicos, sino de las relaciones entre los hombres, es decir del matrimonio, del contrato, del testamento, de donde resultan derechos», nos deja perplejos la existencia de tal malentendido en un teórico del derecho. ¿Por qué está alguien jurídicamente obligado a hacer lo que ha prometido hacer a otro, es decir, por qué debe tal persona comportarse, conforme al derecho, de tal forma? ¡Esta pregunta se refiere al fundamento de conocimiento de dicho juicio de deber-ser y no a su causa temporalmente previa! Sólo en la medida que la promesa dada y aceptada es pensada como condición de un deber-ser, constituye tal promesa un contrato vinculante. ¡Y dicho deber-ser no puede percibirse como un hecho-de-ser(Seinstatsache) -como el hecho del contrato- ni deducirse a partir de juicios-de-ser (Seinsurteilen)! Sólo cuando presupongo un enunciado que declara que bajo determinadas circunstancias determinadas personas deben comportarse de una determinada forma, es decir, sólo en la medida en que se presupone una norma, puedo llegar a mantener la existencia de una obligación y, con ello, suponer la existencia de un contrato vinculante. ¿Es posible que sea todavía necesario repetir estas obviedades? La cima de la confusión tiene lugar cuando Ehrlich replica enfáticamente a la concepción -por él combatida- que establece una relación entre el enunciado jurídico y los hechos relevantes desde un punto de vista jurídico: «Los fenómenos sociales no pueden explicarse construyéndolos jurídicamente (...)» (cf. p. 28). De acuerdo, pero ¿cuándo se habría equivocado tanto la jurisprudencia como para «explicar» los «fenómenos sociales»a través de la relación lógica entre un enunciado jurídico y un estado de cosas?

Si por «enunciado jurídico» entendemos, como es usual, las 
normas jurídicas generalmente vinculante, es lógicamente imposible concebir las relaciones jurídicas sin la presuposición (lógica) de tales enunciados jurídicos. La terminología de Ehrlich se aparta, en efecto, de lo usual. El concepto de enunciado jurídico, que en la obra de Ehrlich tiene una significación tan preeminente que casi asemeja dicha obra a una teoría de las normas -los conocimientos más importantes están en relación con dicho concepto-, no tiene parangón por su carácter oscuro y vacilante. Se insiste en que «una norma jurídica no debe confundirse con un enunciado jurídico. El enunciado jurídico es la forma fortuita y generalmente vinculante de una disposición jurídica en un código o texto legal» (p. 29). Normas jurídicas establecidas en códigos y otros textos legales $\mathrm{y}$, por tanto, fijadas por escrito, sólo existen, naturalmente, en un momento avanzado del desarrollo. ¿Había dudado alguien de esto? El gran descubrimiento de Ehrlich, a saber, que en los tiempos remotos no existían enunciados jurídicos, ¿tiene que conducir a tamaña trivialidad? En interés de la obra de Ehrlich, no queremos llegar a esta conclusión. Pero por enunciado jurídico tampoco podemos entender los enunciados gramaticales de una ley o de un código. ¡Tal concepto no tendría en modo alguno un significado dogmático! ¿Qué es entonces un «enunciado jurídico» en el sentido ehrlichiano? «Una norma jurídica» que debe ser distinguida de un enunciado jurídico, «el mandato jurídico incorporado en la acción tal y como dicho mandato impera, incluso sin una forma verbal, en una determinada y quizá completamente reducida colectividad» (p. 30). De acuerdo, una norma jurídica es un «mandato jurídico». ¿En qué se diferencia, entonces, un «mandato jurídico» de una «disposición jurídica», que es como se caracteriza el enunciado jurídico? El mandato jurídico debe ser «incorporado a la acción» para poder ser una norma jurídica. Y si la norma jurídica no es observada -esto es, si la norma no es incorporada a la acción- ¿quiere esto decir que no tiene todavía el carácter de norma jurídica? ¿Qué quiere decir: «sin una forma verbal»? ¿No debe ser verbalizable todo mandato jurídico, toda disposición jurídica? ¿Cómo podrían comunicarse sino a través de palabras las disposiciones o mandatos jurídicos? Que éstos no tengan que ser necesariamente establecidos por escrito en códigos u otros textos legislativos, es evidente. Si los enunciados jurídicos «han terminado por ser realmente efectivos, de dichos enunciados jurídicos resultan normas jurídicas». ¡Ni con la mejor voluntad se puede imaginar algo como lo dicho en la frase anterior! «En toda sociedad hay muchas más normas jurídicas que enunciados jurídicos, puesto que siempre hay mucho más derecho referido a las relaciones singulares que referido a todas las relaciones similares, 
de la misma forma que también hay más derecho del que son conscientes los juristas contemporáneos que tratan de formularlo verbalmente» (p. 30). De acuerdo, pero ¿cómo es posible que el derecho venga referido a una relación singular cuando el derecho es una regla? Para que pueda hablarse de derecho ¿no deben tratarse de la misma forma todas las relaciones similares que tienen lugar dentro de la sociedad jurídica? ¿Qué significa, entonces, el «orden interno» de la colectividad que Ehrlich opone a los enunciados jurídicos generales, sino que determinadas relaciones similares dentro de la colectividad deben ser determinadas de la misma forma? De este «orden interno» que no se compone de enunciados jurídicos y que significa derecho antes de que existan enunciados jurídicos, Ehrlich dice, por ejemplo: este orden interno «determina las condiciones y consecuencias de un matrimonio válido». ¿De un único matrimonio o de cada matrimonio que se celebra en el seno de la colectividad? ¿Estamos en presencia del «derecho» para una relación «individual» o «para todas las relaciones similares» El mismo Ehrlich dice en otro lugar (p. 96): «Un hecho individualizado en la sociedad no es un hecho social... sólo una vez que se hace general puede mostrarse como un componente del orden social». ¡Ehrlich dice que hay más normas jurídicas que enunciados jurídicos porque hay más derecho del que son conscientes los juristas cuando lo formulan verbalmente! ¿Pero qué tienen que ver aquí, de repente, los juristas? ¿Es que una disposición jurídica no es un enunciado jurídico, sino es formulada verbalmente por un jurista? ¿Puede haber un derecho del que nadie sea consciente, que no sea formulado verbalmente por alguien, mejor dicho, que no sea formulable verbalmente? ¿Qué se debe pensar, sin embargo, de la distinción completa y fundamental en la obra ehrlichiana entre enunciado jurídico y norma jurídica cuando Ehrlich, tras haber declarado en las páginas 22 y 29 que el enunciado jurídico -a diferencia de la norma jurídica- es formulado verbalmente, afirma en la página 135 refiriéndose a la diferencia entre las normas jurídicas y las otras normas: «Por otra parte, la norma jurídica, a diferencia de las otras normas, es siempre expresable con palabras claras y determinadas. Dicha norma jurídica da estabilidad a las colectividades que reposan sobre la norma jurídica... las normas de la moral y de las buenas maneras también se convierten en normas jurídicas tan pronto como emergen de su generalidad y son formuladas con palabras claras»? ¿Y qué se debe entender bajo el término ehrlichiano «enunciado jurídico» cuando afirma en la página 39 que éste es una «disposición jurídica» cualificada y en otra parte que el ordenamiento jurídico vinculante se compone, al menos en 
parte, de tales «enunciados jurídicos», mientras que en la página 138 identifica el concepto de enunciado jurídico con el de ley formal, desdiciéndose, por tanto, y dándole la vuelta completamente a la terminología: «En la forma del enunciado jurídico, especialmente en la forma de la ley, pueden incorporarse los contenidos más diversos. Existen, por tanto, enunciados jurídicos sin contenido normativo, sin contenido legal vinculante, leyes en el sentido formal». ¡Aquí toda crítica se ha hecho imposible! La manera en que Ehrlich va dando saltos de un lado para otro con estos conceptos fundamentales para su sistema no tiene precedente. Por un lado afirma en la página 30 que la norma jurídica es el derecho para una relación individual (por oposición al enunciado jurídico que está vigente con carácter «general» o para «relaciones similares»); por otro lado define las «normas» en la página siguiente como «mandatos y prohibiciones abstractos» y mantiene -lo que es ya francamente inconcebible- que forma parte de la esencia de la norma el que ésta se refiera a la convivencia humana: ¡de manera que las reglas lingüísticas, las reglas del gusto o de la higiene no son normas ${ }^{5}$ !

${ }^{5}$ Junto a los conceptos de «norma jurídica» y «enunciado jurídico», señala Ehrlich las «normas de decisión» y caracteriza como la primera y más importante tarea de la ciencia del derecho sociológica (p. 33) «el distinguir de las simples normas de decisión las partes constitutivas del derecho que regulan, ordenan y determinan la sociedad». Desgraciadamente debo renunciar, dado el espacio del que dispongo, a un análisis extenso de aquella parte de la obra de Ehrlich que «aporta la solución a esta primera y más importante tarea de la ciencia sociológica del derecho». En medio de esta madeja de contradicciones, me limito a llamar la atención sobre la más grosera. La norma de decisión con arreglo a la cual debe decidirse un proceso que es entablado como consecuencia de una infracción, es completamente diferente de la regla de derecho viva y efectiva en la sociedad según la cual actúan efectivamente los hombres (p. 33). Sin embargo, la norma de decisión (p. 98) es una regla con arreglo a la cual no sólo deben actuar, sino que de hecho actúan regularmente los tribunales, que constituyen una parte, si bien especial para la sociología del derecho, no por ello menos significativa de la sociedad humana. ¡En Ehrlich, por tanto, la regularidad sociológicamente relevante se detiene de hecho ante los tribunales! ¡Las normas que los tribunales aplican a través del aparato coactivo no representan ninguna realidad viviente! Para ilustrar la oposición fundamental entre regla de derecho «viva» y «mera» norma de decisión se refiere Ehrlich al siguiente ejemplo: «si en una región constituye una regla el que el hombre disponga ilimitadamente del patrimonio de la mujer, entonces, la disposición por parte del hombre del patrimonio de la mujer será considerada como vinculante para aquélla (esta es la norma de decisión) con independencia de que en una determinada familia se haya actuado así» (¡la regla de derecho viva!) (p. 300). Se puede cuestionar cómo el derecho de una familia concreta puede estar en contradicción con el derecho habitual de una región, pero lo que desde luego es inconcebible es cómo la norma de decisión, esto es, según la suposición de Ehrlich, una regla efectiva en un círculo 
Si aceptamos la determinación conceptual del derecho que hace Ehrlich (que el propio Ehrlich califica como única «científica») como «regla de la acción humana» y como «orden», entonces todo orden jurídico debe ser un conjunto de reglas. En la página 68, sin embargo, nos encontramos con la siguiente afirmación: «El derecho no se compone de enunciados jurídicos sino de instituciones jurídicas»(Rechtseinrichtungen). Entonces el derecho podría estar formado, desde un cierto punto de vista, por enunciados jurídicos, es decir por reglas jurídicas (en el sentido de reglas-de-ser o de deber-ser) y al mismo tiempo consistir en una serie de instituciones jurídicas (en la medida en que bajo la expresión

importante (o, tomando otro ejemplo, «lo que en general es habitual en un país», esto es, de ninguna forma las «nuevas» reglas de los tribunales) se debe oponer a las reglas vivas que ordenan fácticamente la sociedad. Del mismo modo es incomprensible que Ehrlich mantenga que la «nueva» norma de decisión, que es caracterizada en oposición a la regla viva de derecho, «es extraída del orden interno de la colectividad por el juez en cada proceso», «del hecho del derecho», es decir, del ordenamiento jurídico en el sentido de regla viva de la acción sobre la que «se basa en un primer análisis» (p. 98) la norma de decisión. Constituye una contradicción evidente a lo que se acaba de decir, el que Ehrlich afirme que la norma de decisión es «siempre algo diferente del orden interno» (p. 99); asimismo supone una inversión completa de la oposición que se contempla (norma de decisión / regla de la acción) el hecho de que Ehrlich mantenga (p. 102) que en las normas de decisión «no se presupone un orden vivo, sino una lucha por uno muerto: en efecto, mientras que ahora caracteriza la regla de la acción (Regel des Handels) que se ha infringido (a causa de la única violación que el propio Ehrlich quiere tratar en otro momento como excepción sin importancia) como orden muerto, Ehrlich había contrapuesto en un principio este orden, en tanto que regla viviente, a la norma de decisión. Aunque frente a la regla de derecho propiamente dicha Ehrlich caracteriza la norma de decisión -de forma completamente infundada por otra parte- como una regla que aparece «creativamente», es decir, a través de la invención libre del individuo -en último término, toda norma jurídica se origina de esta forma-, vuelve a afirmar en otra parte que tal norma hay que «extraerla a partir de un principio general, no de lo arbitrario» (p. 98). Ehrlich tan pronto afirma que la norma de decisión es la norma a través de la cual se determina la consecuencia de la infracción o la obligación de reparar el daño, como mantiene que la decisión según la cual un concreto supuesto de hecho queda comprendido dentro de un concepto contenido en un enunciado jurídico (por ejemplo que un objeto dado constituye una "accesión”), tiene como base una norma de decisión. Aquí habla Ehrlich de normas de decisión «concretas» en oposición a las «abstractas». A continuación presenta Ehrlich como importante conocimiento sociológico la opinión que mantiene que la mayoría de los «enunciados jurídicos» proceden de «normas de decisión», siendo aquí las normas de decisión lo «concreto» que precede a lo «abstracto» del enunciado jurídico. Lo hasta ahora expuesto basta para justificar la impresión de que es prácticamente imposible hacerse una idea aproximada de lo que Ehrlich entiende por "normas de decisión", y ello teniendo en cuenta el importante papel que éstas juegan en la «Fundamentación». 
«institución jurídica» o instituto jurídico no se entienda -según la terminología 
dominante- otra cosa que una suma de enunciados jurídicos correspondientes a uno y el mismo fin). Como ejemplo de «instituciones jurídicas», se refiere Ehrlich a las siguientes: estado, iglesia, municipio, familia, propiedad, herencia. No se toma en consideración la cuestión de saber si todos estos conceptos deben ser efectivamente subsumidos asimismo bajo la categoría «instituto jurídico». Propiedad, familia, contrato, herencia son indudablemente instituciones jurídicas. ¿Pero qué imagina Ehrlich bajo estas «instituciones jurídicas»? O bien son hechos físicos o psíquicos o acaecimientos del mundo externo (desde el punto de vista del observador [Betrachter], o bien constituyen algún tipo de significado que viene adscrito a tales hechos o acaecimientos por el observador (Betrachter) sobre la base de ciertas normas que son presupuestas.

Ehrlich afirma correctamente (teniendo a la vista un concepto normativo de derecho) lo siguiente: «El derecho y las relaciones jurídicas son una cosa intelectual (gedankliches Ding) que vive en la cabeza del hombre y no en la realidad tangible, perceptible a través de los sentidos» (p. 68). Pero la realidad no sólo es perceptible a través de los sentidos corporales, es decir, exteriores, sino también a través de los sentidos interiores. El derecho y las relaciones jurídicas no son, evidentemente, una realidad psíquica del mundo exterior (desde el punto de vista del observador [Betrachter]. Si no fuera así, la jurisprudencia constituiría una rama especial de la psicología. La afirmación de que un hecho es ilícito o de que alguien está obligado a algo no expresa ni un hecho corporal ni un hecho mental del mundo exterior (del que realiza la afirmación). Tampoco expresa que un determinado acto mental tiene lugar en el mundo exterior. ¡Alguien está obligado a algo aunque no piense en ello ni lo sienta o lo desee! No se expresa con esto en modo alguno un ser -ni corporal ni mental (el mundo exterior)- sino un deber-ser, es decir, se afirma cualquier hecho corporal o mental como contenido de un deber-ser, como contenido de una norma presupuesta como válida por el que la declara. Esto y no otra cosa significa la frase de que el derecho no es perceptible por los sentidos, sino que es un objeto intelectual. Ehrlich prosigue diciendo: «el derecho no existiría si no existieran hombres que tuvieran representaciones intelectuales del derecho». Esta afirmación es correcta en el sentido de que no habría pensamiento si no hubiera hombres pensantes: un hecho psicológico que, ciertamente, no es relevante para el conocimiento de la esencia del derecho. Se tiene la impresión de estar ante un enigma cuando Ehrlich afirma en la frase siguiente algo completamente opuesto a lo que acababa de decir. Ehrlich acababa de decir que el derecho es una represen- 
tación que no tiene como contenido algo que sea perceptible por los sentidos. A continuación, afirma: "También aquí nuestras representaciones están hechas de un material que obtenemos de la realidad tangible, perceptible por los sentidos». ¿Qué podríamos añadir a esto? Más adelante afirma: «Siempre subyacen a nuestras representaciones hechos que hemos observado. Tales hechos deben haber estado presentes antes de que haya surgido en el cerebro humano el pensamiento sobre el derecho y sobre las relaciones jurídicas». ¿Qué quiere decir que hay hechos que subyacen a nuestras representaciones? Hay representaciones de hechos y hay representaciones que no tienen a los hechos como contenido. Las representaciones del bien y del mal no son un hecho; la acción es un hecho que está unida a la representación de lo bueno o de lo malo. Si el derecho fuera un hecho o el concepto de derecho una abstracción a partir de hechos, entonces el derecho no sería un simple «objeto intelectual». ¡El derecho sería entonces perceptible por los sentidos, observable! "Y también en el presente deben existir ciertos hechos antes de que podamos hablar de derecho o de relaciones jurídicas». Esto podría ser correcto en la medida en que el derecho y las relaciones jurídicas vinieran expresados por un hecho, es decir en la medida en que se expresara una relación entre un hecho y una norma jurídica. Sin embargo, la norma jurídica es derecho sin necesidad de tener que referirla a un hecho concreto. Un hecho nunca es derecho o relación jurídica precisamente porque, en tanto que ser, es un hecho dado, valorativamente indiferente en sí, carente de significado en la medida en que no es puesto en relación con una norma, es decir, con un valor objetivo, en otras palabras, en la medida en que un estado de cosas no es pensado bajo la forma del ser sino bajo la del deber-ser. Por ello no es sólo incorrecto, sino contradictorio respecto a la concepción (errónea) expresada líneas arriba por Ehrlich, el hecho de que éste afirme: «aquí (es decir, en los hechos) también hay que buscar el lugar donde se fragua el derecho». Y «la primera cuestión de la ciencia del derecho es», tal y como Ehrlich la formula como resultado de esta argumentación completamente confusa: «¿Qué instituciones efectivas se convierten en relaciones jurídicas con el paso del tiempo y a través de qué procesos sociales sucede esto?» Esta pregunta, tal y como está formulada, no tiene respuesta dado que carece de sentido. Para un modo de consideración (Betrachtung) centrado en la efectividad (Tatsächlichkeit) sólo hay hechos, realidades (Wirklichkeiten), y no valores. Para el conocimiento, un valor no puede ser el resultado, a través de una evolución, de una realidad, precisamente porque el valor está dado a una dirección de conocimiento diferente de la que se ocupa de la realidad 
(Wirklichkeit). No una ciencia del derecho que se ocupa de lo lícito y de lo ilícito, del deber $\mathrm{y}$ de la pretensión, esto es, de conocimientos valorativos, sino una psicología social explicativa que se ocupa exclusivamente de datos de la realidad perceptibles, puede plantear el problema de saber de qué forma surgen ciertas representaciones de deber-ser (Sollvorstellungen), ciertas normas como hechos psíquicos reales; sólo esta ciencia puede quizá plantear la cuestión de saber - y éste sería su objeto por excelencia- qué causas originan el que hombres pertenecientes a un determinado grupo y época procedan efectivamente a hacer valoraciones, y en concreto, procedan a hacer valoraciones jurídicas. Dicha sociología no tiene nada que ver con el valor sino con las valoraciones; no es una ciencia valorativa sino valuo-explicativa (werterklärende). Para dicha ciencia el derecho no es una norma que se presupone como válida, no es un valor objetivo, sino un proceso natural e indiferente desde un punto de vista valorativo, un determinado comportamiento intelectual y corporal del hombre cuya regularidad debe ser aprehendida. Su objeto es, estrictamente hablando, no el derecho sino el pensar, el sentir o el querer del derecho, lo que los hombres opinan del derecho y lo que, con arreglo a esa opinión, hacen o dejan de hacer. Tal modo de consideración (Betrachtungsweise) no conduce jamás al enunciado "esto es lícito o ilícito», es decir, «esto debe o no debe ser», sino a los enunciados: «se piensa o se hace esto», es decir, «esto es o fue». Los conocimientos a los que llega este modo de consideración (Betrachtungsweise) sociológico son por ello no-valorativos (wertfrei), como los de la biología. La diferencia entre dicha sociología y la ciencia del derecho (en sentido normativo) es la misma que existe entre una historia natural de las representaciones morales del hombre y una ética dogmática, o la que existe entre una historia de la religión y una teología. La funesta confusión de Ehrlich radica en que no sabe distinguir los dos modos de consideración (Betrachtungsweise), es decir que apunta hacia un modo de consideración explicativo (una explicación-de-ser sociológica), mientras que al mismo tiempo siempre regresa a un concepto normativo de derecho, al punto de vista de la valoración científica.

Ehrlich considera como un resultado importante de su investigación sociológico-jurídica el conocimiento de lo que él llama «el hecho del derecho». ¿Qué es lo que entiende como tal? Aquellos hechos «a los cuales el intelecto humano refiere (anknüpft) las 
reglas», reglas según las cuales viene representada la organización de los grupos humanos en colectividades, reglas «que atribuyen a cada individuo su puesto en la colectividad» (pp. 68-69). No se entiende lo que quiere decir que una regla «esté referida a un hecho». Parece que no hay que entender otra cosa que una regla que se refiere a un hecho como objeto de la regulación. Por tanto, los hechos del derecho parecen constituir los objetos de las regulaciones jurídicas. Como ejemplo de tales hechos menciona Ehrlich: «el ejercicio, el dominio, la posesión, la declaración de voluntad» (p. 69).

El «ejercicio» debe ser algo diferente, según Ehrlich, del derecho consuetudinario; ejercicio quiere decir aquí: «lo que hasta ahora se ha hecho, ha de ser la norma para el futuro». Sin embargo, el derecho consuetudinario constituye indudablemente tal «ejercicio». «A través del ejercicio son determinadas la posición del jefe, de los órganos, así como de los súbditos de la colectividad (las posiciones de dominación y de subordinación), y las tareas del individuo». Es por ello que el «ejercicio» debería ser el único hecho del derecho propiamente dicho, puesto que unas líneas más arriba Ehrlich ha señalado como hecho del derecho todo hecho al que vienen referidas las reglas «que asignan a cada individuo su puesto y tarea en la colectividad» (p. 68). El «ejercicio», a diferencia de la posesión, el contrato o las relaciones de dominio, podría no entenderse como «un hecho del derecho» en el sentido de un objeto de la regulación, dado que el «ejercicio» es la regla misma, es decir que se trata de otra forma de indicar que un hecho se repite regularmente. La posesión, los contratos y las relaciones de dominio, son «ejercitados», es decir se repiten regularmente, son el contenido de una regla pero no el ejercicio mismo. Cuando cualquier relación de dominio o de posesión, cuando cualquier declaración de voluntad se convierte en un hecho jurídico a partir de elementos puramente fácticos, esto sólo sucede evidentemente a través del ejercicio. En palabras de Ehrlich: «lo que hasta ahora se ha hecho, ha de ser la norma para el futuro». Mejor dicho: lo que se ha ejercido regularmente se convierte en el contenido de una representación de deber-ser (Sollvorstellung), de una norma que exige que aquello debe ser. Y bajo la presuposición de tal norma, los hechos tipificados por ella pasan a ser jurídicamente relevantes. En este sentido, el ejercicio es el camino a través del cual los hechos se convierten en hechos del derecho. ¡Pero el ejercicio en sí no es un hecho del derecho!

Parece que Ehrlich entiende por «ejercicio» el mantenimiento de un tipo de relación de dominio completamente determinado, a saber las relaciones de dominación y de subordinación, el posicio- 
namiento de los órganos de la colectividad. Pero en realidad se trata más bien de relaciones de dominio y de declaraciones de voluntad -es decir, según Ehrlich, otros dos hechos del derecho que, a través del ejercicio, han pasado al contenido de las normas. En vano intentamos alejarnos de esta confusión conceptual cuando Ehrlich afirma que «las relaciones de dominio y de sometimiento (Herrschafts- und Unterwerfungsverhältnisse) deben diferenciarse de las relaciones de superioridad y de subordinación (Über- und Unterordnung) presentes en toda colectividad organizada y en las que se expresa el orden interno de la misma». ¡Ehrlich es más estricto que sus más severos críticos a la hora de crear conceptos y distinciones! Una colectividad organizada en relaciones de superioridad y de subordinación ¿no es una organización «de dominación»? «El mandato que tiene su origen en la subordinación organizativa es diferente del mandato dado en virtud del dominio (der Befehl infolge organisatorischer uberordriung is etwas anderes ais der Befehl Kraft Herrschaft). El primero es impuesto por el que manda a la colectividad, el segundo se lo impone aquél a sí mismo» (p. 71). Pero ambos mandatos, en la medida en que son obedecidos, ¿constituyen todavía relaciones de dominio para un modo de consideración sociológico?

Ehrlich distingue dos tipos de relaciones de dominio: las que resultan del grupo familiar -el sometimiento de los hijos al poder paterno, materno o parental- y las relaciones de subordinación de origen puramente social, como, por ejemplo, la esclavitud o las de servidumbre» (p. 71). Pero la familia, ¿no tiene carácter social? Las relaciones de dominio que resultan de la misma, ¿no tienen también un origen «puramente social»? La diferencia radica en el hecho de que ciertas relaciones de dominio y de explotación se atenúan a través de relaciones de naturaleza sexual. La oposición entre las tendencias económicas y las tendencias sociológicas debería ser el objeto de una investigación sociológica y no jurídico-sociológica. Es evidente que, a través de su ejercicio, determinadas relaciones de dominación aparecen en la conciencia del hombre como debidas, es decir que se convierten en el contenido de normas. Sin embargo, es incorrecto atribuir a la concepción dominante, como hace Ehrlich, la idea inconcebible de que en un principio sólo habría habido enunciados jurídicos que habrían ordenado ciertas relaciones de dominación, las cuales sólo habrían aparecido precisamente como consecuencia de los enunciados jurídicos: «De hecho siempre se ha supuesto que es el enunciado jurídico el que somete a la mujer al hombre, los hijos a la autoridad parental, el pupilo al tutor y los sirvientes a su señor, pero el hecho de la dominación y del sometimiento siempre fue anterior 
al enunciado jurídico que lo regulaba como una parte constitutiva del ordenamiento jurídico» (p. 71). ¡De nuevo tiene lugar la confusión entre presuposición lógica de la norma jurídica y precedencia temporal de un hecho! Para comprender la relación entre padre e hijo, señor y esclavo, como una relación de dominación, se debe presuponer una norma -emanada de cualquier forma por parte del que enuncia ese juicio de valor de carácter jurídico. Eso y no otra cosa significa: «referir (zurückführen) las relaciones de dominación y de sometimiento a las disposiciones jurídicas». La concepción de la «doctrina dominante» es absolutamente compatible con el hecho evidente que hasta ahora no ha sido negado por nadie, a saber, que las relaciones de dominación han existido antes de que se formaran las normas sobre dichas relaciones de dominación en la conciencia de los hombres.

También los conocimientos sociológicos que Ehrlich obtiene a partir de la posesión como hecho del derecho son obviedades que nadie pone en duda. Ningún teórico del derecho o historiador ha cuestionado que la propiedad, como instituto jurídico, es decir, lo que las normas jurídicas caracterizan como tal, surgió en la conciencia de los hombres con posterioridad al hecho del dominio sobre una cosa; en otras palabras, que la posesión y no la propiedad es lo originario (p. 76). Tampoco se ha cuestionado que las normas jurídicas de las que puede abstraerse el concepto romano de propiedad no surgieron de la nada en el comienzo del desarrollo jurídico. Tampoco es cierto que «la doctrina del dominio absoluto sobre la cosa es presentada de forma tal como si agotara todo el contenido de la propiedad, como si no existieran el derecho forestal, el derecho de las aguas, el derecho agrario, el ordenamiento urbanístico o el comercial» (p. 81). Preguntarse si el concepto romano de propiedad tiene todavía algún sentido con respecto a las disposiciones actuales del derecho administrativo, es una cuestión justificada, pero no es relevante para la sociología, para la conceptualización normativa. También carece de fundamento afirmar lo siguiente: «la posesión se convierte en relación jurídica a través de su incorporación en el orden económico». Esto significa que el orden económico se considera al mismo tiempo un orden jurídico. Que determinados hechos económicos contribuyen a la aparición de normas jurídicas sobre la propiedad, no debería ser un secreto para nadie. No obstante, sólo si se presuponen tales normas jurídicas, la posesión es una relación jurídica. Sería desde luego un problema interesante mostrar a través del material histórico, y para una sociedad concreta, cómo aparecen tales normas jurídicas. A este respecto no hay huella alguna en la obra de Ehrlich. 
Ehrlich ofrece un esquema de desarrollo de la declaración de voluntad, y especialmente del contrato, que debe calificarse completamente como construcción y que no se basa en un material inductivo. En todas las zonas del planeta en las que el ordenamiento jurídico contiene normas sobre el contrato, el desarrollo debe haberse producido de la siguiente forma: «Se deben distinguir los siguientes grados en la evolución del acuerdo como hecho del derecho: contrato de efectivo (Barvertrag), contrato de deuda (Schuldvertrag), contrato de fianza (Haltungsvertrag) y contrato de crédito (Kreditvertrag)» (p. 87). Dicha evolución es plausible, pero Ehrlich no ofrece ningún dato que permita afirmar que esto siempre ha ocurrido así, sino que apela a los «resultados de la ciencia y de la historia del derecho comparadas» (p. 89). Acerca de la relación entre, de una parte, la obligación (Schuld) y la responsabilidad, y de otra, el contrato -no es éste el lugar para desarrollar una crítica de esta no muy afortunada conceptualización del derecho alemánEhrlich afirma lo siguiente: «la obligación es el deber-ser del obligado, es lo que constituye, según la regla de la vida (Regel des Lebens) el contenido de un compromiso. La responsabilidad es el derecho de sujeción que tiene el acreedor, que queda satisfecho incluso contra la voluntad del deudor; el acuerdo deja de ser mero hecho para pasar a ser un hecho del derecho, esto es, un contrato, aun cuando de dicho acuerdo sólo resulta una obligación y no una responsabilidad» (p. 84). Ehrlich insiste en que «para la vida económica lo importante es la obligación, y no la responsabilidad, y que en la mayoría de los casos es casi indiferente el hecho de que un contrato sea ejecutable cuando lo que importa con respecto a su cumplimiento es la regla de la acción que domina la vida (die Regel des Handelns, die das leben beherrscht)» (p. 88). Finalmente constata que «es, por ello, necesario establecer no sólo en la historia, sino también en el derecho vigente, el hecho de que junto a las convenciones que existen completamente fuera del derecho, existen contratos que indican una obligación pero no una responsabilidad, sólo una regla según la cual los hombres se orientan en la vida y no una regla según la cual proceden las autoridades, y que dichos contratos son tan importantes para la vida económica como los contratos ejecutables» ${ }^{6}$ ( $\mathrm{p}$.

${ }^{6}$ La posición doctrinal -representada aquí por Ehrlich- que pretende que en el desarrollo del derecho alemán los contratos habrían fundamentado una obligación y no una responsabilidad, es completamente ambigua. Amira ha subrayado con énfasis (vid. su recensión de la obra de Gierke sobre «Obligación y Responsabilidad», en Zeitschrift für Rechtsgeschichte, vol. XXXI, p. 486) que la distinción entre culpa y responsabilidad es una simple «diferencia lógica», así 
$80)$.

como que es un error mantener que la obligación y la responsabilidad sólo «se han desarrollado conjuntamente» en el curso de la evolución histórica. Asimismo Schwerin afirma lo siguiente (Deutsche Rechtsgeschichte, p. 57, nota 6): «es inimaginable que en algún momento el deudor haya podido -por regla general- no ser responsable».

Si «obligación» quiere decir «deber-ser jurídico», sólo se puede hablar de aquélla si la comunidad jurídica dispone de una posibilidad de reacción contra la violación de la misma, esto es que la comunidad jurídica dispone de la posibilidad de ejecutar incluso contra la voluntad del deudor. Es completamente erróneo el que Ehrlich identifique las obligaciones que sirven de base a la responsabilidad con las obligaciones ejecutables, esto es, cuyo cumplimiento puede ser exigido ante los tribunales. Todo vínculo jurídico ha sido y es, en el derecho alemán, ejecutable, y traía como última consecuencia la privación de libertad y la confiscación de bienes; en otras palabras, en aquellos casos en los que no existía un objeto especial de ejecución (una garantía, por ejemplo), el deudor respondía con su persona y con su patrimonio. 
En contra de esto debería plantearse la cuestión de saber cómo aquellos contratos «que existen completamente fuera del derecho» pueden distinguirse de aquellos que indican una obligación pero no una responsabilidad, en el sentido de que contra su violación no existe una reacción específica de la comunidad jurídica (o una reacción de aquella comunidad específica). Toda convención -incluso la no-jurídica- en la medida en que se presupone su carácter vinculante, indica una obligación en el sentido de que las partes en dicha convención deben comportarse con arreglo a la misma. Este deber-ser puede ser un deber-ser moral o un deber-ser de las costumbres, según se presuponga una norma de la moral o de los buenos modales. Pero ¿cuándo un contrato es jurídico, un deber-ser jurídico y la obligación jurídica? ¿Cuál es el criterio para ello sino la posibilidad de una reacción específica de la comunidad jurídica organizada, esto es, la «responsabilidad» en el sentido ehrlichiano que identifica responsabilidad con la posibilidad de ejecutar (ante los tribunales)? ¿Quién ha puesto en duda que los contratos no ejecutables y que no dan lugar a una responsabilidad puedan tener una gran importancia para la economía? ¿Pero son el derecho y la economía la misma cosa? Ciertos deberes morales ¿no tienen una gran significación para la sociedad y para el individuo? ¿Quiere decir esto que dichos deberes deben ser, por tanto, deberes jurídicos? Ehrlich no deja sin respuesta la pregunta que interroga por la esencia de las normas o de las reglas y cuya explicación constituye el objeto específico de su sociología del derecho que se distingue como disciplina especial de la teoría general de la sociedad. Ehrlich reconoce la necesidad de delimitar el objeto de su nueva ciencia frente al de una sociología de la moral, de las costumbres, del arte o de la religión. Pero 
¿cómo traza los límites? La importancia de la pregunta y la singularidad de la respuesta que ofrece la respuesta que ofrece Ehrlich justifican una cita más extensa:

«Mientras que también es difícil trazar científicamente los límites entre las normas jurídicas y otros tipos de normas, en la práctica esta dificultad se presenta raramente... la cuestión de la oposición entre normas jurídicas y normas extrajurídicas no es una cuestión propia de la ciencia social, sino de la psicología social.»

¿Quiere esto decir que la «psicología social» no es una ciencia social y que la cuestión que tiene como finalidad nada menos que delimitar el objeto de conocimiento de la sociología del derecho en realidad no puede ser una cuestión de la ciencia social? La posible objeción que podría formularse a esta posición la desvanece Ehrlich a través de la siguiente solución al problema:

«los diferentes tipos de normas producen diferentes reacciones (Gefühlstöne); a la transgresión de las diferentes normas se responde con diferentes sensaciones. Así, se puede comparar el sentimiento de sublevación que produce la violación del derecho con la indignación que produce la violación de un precepto moral, con el rechazo a causa de una indecencia, con el enfado que produce una falta de tacto, con el ridículo que produce la ausencia del buen tono y, finalmente, con el desprecio que experimentan los caballeros (Modehelden) frente a aquellos que no están a su altura» (p. 132).

¡Entre los no pocos intentos de determinar la esencia del derecho éste constituye seguramente la cima de la curiosidad! Y hay que lamentar ciertamente que la «doctrina dominante» no se haya apropiado todavía de esta teoría, porque en ese caso sería un placer poder admirar la ironía de la crítica ehrlichiana. Pero está reservado a Ehrlich el poder distinguir entre el sentimiento de «sublevación» y el de «indignación», entre la «reacción» (Gefühlston) de «rechazo» y la de «desprecio», entre la de «enfado» y la de «ridículo». Esta psicología de un sociólogo observador de la realidad se aproxima ciertamente a las orgías de la jurisprudencia psicológica que se ocupa de «abstracciones vacías». Para poder medir la utilidad de los criterios ehrlichianos basta con imaginar, de una parte, la norma jurídica que dispone que hay que pagar por anticipado el precio del alquiler o la que dispone que hay que pagar el 6 por 100 de intereses en las transacciones comerciales -ambas reglas de la vida (Regeln des Lebens) y no meras normas de decisión (que desde luego también son 
normas)- y de otra 
parte, la norma moral de la caridad o la de la sinceridad. ¡Qué similares son el sentimiento de «sublevación» ante la violación de las primeras y el sentimiento de «indignación» ante la violación de las segundas! ¿O quizá es la «indignación» la que acompaña a la violación de una norma jurídica y la «sublevación» la que resulta de una inmoralidad? Pero quizá son muchos los que se «sublevan» ante una falta de tacto y al mismo tiempo dicen que están indignados y otros muchos que sólo «se enfadan» ante una violación del derecho. En vuestras reacciones debéis reconocer las normas, se dice, pero hay muchos que se han puesto en «ridículo» y con ello han infringido normas distintas de las del buen gusto. Es una diversión demasiado fácil intentar examinar los criterios ehrlichianos sobre las categorías de normas, sobre todo cuando aquellos parecen no satisfacer ni al mismo Ehrlich. Así, nuestro autor tiene la necesidad de caracterizar las normas jurídicas a través de una forma diferente a la del sentimiento de sublevación que produce su violación. Ehrlich dice -aparentemente explicando su teoría, pero en realidad aludiendo a un criterio completamente diferente- que

«la norma jurídica es propiamente el sentimiento que los juristas de derecho común han denominado opinio necessitatis. Con arreglo a ésta se debe reconocer la norma jurídica» (p. 132).

La opinio necessitatis en el ejercicio es algo distinto del sentimiento de sublevación ante la violación de una norma. Pero con independencia de esto ¿cuál debe ser la diferencia entre derecho y moral? ¿No comporta también la ley moral el carácter de la necesidad? ¿No es la necesidad moral al menos necesidad, como la jurídica?

No se puede tomar en serio a Ehrlich cuando afirma:

«La norma jurídica regula, al menos según el parecer del grupo del que emana, una cosa de gran importancia, de significado fundamental... Sólo los objetos de menor importancia son dejados al resto de las normas sociales» (p. 134).

¿Tiene realmente menor importancia los objetos de las normas morales y religiosas que los de las normas sobre el préstamo o sobre el arrendamiento? Otro intento vacilante de ofrecer un criterio de distinción es aquel -ya examinado- que pretende diferenciar las normas jurídicas de las otras normas basándose en que las primeras vienen caracterizadas por el hecho de «que siempre pueden ser expresadas y vienen formuladas en palabras 
claras y determinadas» (p. 135). Ehrlich olvida que unos capítulos atrás había caracterizado la norma jurídica precisamente a través del hecho de no estar formulada en palabras claras, a diferencia de los «enunciados jurídicos», los cuales tienen, en opinión de Ehrlich, una importancia secundaría para la sociología del derecho. Cuando Ehrlich afirma: «Las normas jurídicas son normas que emanan de los hechos del derecho» (p. 136), está aceptando un criterio completamente nuevo. ¿Qué significa esta nueva determinación? ¿No son los «hechos del derecho»-relaciones de dominación, posesión, declaración de voluntad- los objetos susceptibles de regulación jurídica, y no sólo de ésta sino también de toda regulación social. Pero incluso esta significación, ¿no viene relativizada por el hecho de que Ehrlich continúa diciendo que las normas jurídicas también «pueden resultar de los enunciados jurídicos del derecho estatal y de la doctrina?» Es inaceptable la posición de Ehrlich cuando mantiene que sólo con respecto a estas normas existe la opinio necessitatis. Y ello debido a que Ehrlich asegura que no todas las normas que surgen a partir de los hechos del derecho o de los enunciados jurídicos son normas jurídicas. Sin embargo, sólo con respecto a estas últimas existe la opinio necessitatis. ¿Con respecto a todas o sólo con respecto a algunas de ellas? Es difícil comprender por qué los hechos a partir de los cuales «emanan» no sólo normas jurídicas sino también «normas que no pertenecen al derecho», a saber normas morales, religiosas, etc., se denominan precisamente hechos «del derecho». Finalmente concluye Ehrlich con una confesión ingenua: "A través de esta caracterización no se ha ofrecido una delimitación positiva de las normas jurídicas frente al resto de las normas. Esto presupondría sobre todo una investigación detallada acerca de la naturaleza de las normas de carácter no jurídico» (p. 136). Pero una sociología del derecho, una fundamentación de esta sociología del derecho, ¿sería posible sin dicho presupuesto? A la luz de lo expuesto, ¿debemos seguir cuestionando si los enunciados generales que son el resultado de la investigación de Ehrlich se refieren realmente al derecho como a un objeto delimitado de alguna forma o si no se refieren en general a las reglas del comportamiento social, no siendo en su generalidad más que construcciones vacías y superficiales? 
Un rasgo característico de la sociología del derecho de Ehrlich es la rigurosa separación entre derecho y estado. Ehrlich destaca enfáticamente como uno de los más graves errores de la jurisprudencia actual, el que ésta reconduzca el derecho al estado, «el que ésta sólo reconozca como derecho el derecho estatal, cuando en realidad es el derecho extraestatal o social el que constituye con mucho la parte más importante del ordenamiento jurídico» (pp. 9 y ss., 49 y ss., 110 y ss. y 295 y ss.). No es fácil determinar lo que Ehrlich entiende por derecho «estatal». Tan pronto es caracterizado como el derecho «creado por el estado» (p. 8), como es a continuación identificado con la «ley» o con «el derecho promulgado como ley por el estado» (p. 11), o más tarde es entendido como las reglas que rigen el comportamiento de los tribunales y otras autoridades estatales (por oposición a las reglas de la acción humana general) (p. 15). Posteriormente parece de nuevo como si el derecho estatal fuera la esencia de las normas coactivas estatales (p. 57). Ciertamente derecho estatal y ley son identificados en las páginas 9 y ss., cuando Ehrlich expresa el reproche de que «La jurisprudencia actual sólo estudia el derecho estatal», o en otras palabras:

«¿Dónde se investiga este derecho extraestatal? No es arriesgado afirmar que la investigación, la doctrina y la enseñanza actuales en el continente europeo no se ocupan de otro derecho que la ley» (p. 9).

Sin embargo, en la página 110 se afirma que:

«el derecho estatal debe ser distinguido cuidadosamente de la ley. El derecho estatal no emana del estado según la forma, sino según el contenido. Es un derecho que sólo puede surgir a través del estado y que no puede existir sin el estado.»

En la página 115 se caracteriza la esencia del derecho estatal como el mandato estatal que indica «a los tribunales y a las demás autoridades cómo deben proceder»-. En la página 296 se establece una diferenciación en la esencia del derecho, al distinguir dos tipos principales de derecho estatal.

«El estado tiene dos formas de hacer efectivo el derecho. La primera son las normas de decisión. El estado prescribe a los tribunales y al resto de las autoridades cómo deben decidir los casos que les son sometidos por las partes. La mayoría de las 
normas de decisión son tomadas desde luego del derecho de los juristas: sólo son derecho estatal si han surgido con independencia del derecho de los juristas y si han sido adoptadas para promover fines del estado. La segunda forma son las normas de intervención (Eigriffsnormen). Éstas, ordenan a las autoridades que intervengan sin necesidad de que hayan sido llamadas a intervenir.»

No será fácil determinar qué derecho establecido en forma de ley es derecho social y cuál es estatal, cuál es enunciado jurídico del derecho de los juristas y cuál norma de decisión o, en su caso, norma jurídica en sentido propio, esto es, regla general de la acción. Todo esto, obviamente, entra dentro de la noción de derecho legal (derecho en forma de ley). De cualquier forma, este nuevo concepto de derecho estatal desarrollado por Ehrlich es completamente diferente y mucho más restringido que aquel contra el que nuestro autor dirige un reproche al principio de la obra, a saber, el «derecho estatal» como objeto exclusivo de la jurisprudencia actual que sólo se ocupa de las «leyes». Hay que dudar seriamente de la posibilidad de separar en el seno del derecho originado en la legislación un derecho estatal y un derecho no estatal. En la medida en que las explicaciones de Ehrlich tienen un sentido, el «derecho estatal» es sólo hasta cierto punto delimitable, en la medida en que entendemos como tal el «derecho del estado», es decir el derecho del estado y de la administración.

La aparición del derecho estatal (staatliches Recht) junto al, hasta ahora sólo social, es caracterizada por Ehrlich de la siguiente manera:

«El derecho estatal aparece mucho más tarde que la administración estatal de justicia. El estado creó en un primer momento su propio ordenamiento, el derecho del estado (Staatrechts), y después, al crear las autoridades, le atribuyó sus competencias y prescribió su modo de funcionamiento e incluso el procedimiento.»

Es realmente enigmático imaginar cómo debe ser posible una administración de justicia estatal antes de que exista un ordenamiento estatal, pero este enigma no es nada en comparación con la misteriosa idea de un estado que crea su propio ordenamiento. Puesto que no podemos entender por «estado» otra cosa que un determinado ordenamiento, el problema que se plantea es muy simple: ¿cómo se crea a sí mismo un ordenamiento? Sea como fuera, de las declaraciones de Ehrlich parece desprenderse que el «derecho estatal» es sobre todo (al menos históricamente) derecho del estado, es decir, derecho que emana del 
estado. Es una lástima 
que esta formulación, expresada claramente en la página 115, venga contradicha por el mismo Ehrlich en la página 304:

«Cuando el estado se prescribe a sí mismo o a sus autoridades su posición y sus tareas, no estamos desde luego ante el derecho estatal en sentido propio, sino ante el derecho del estado. Con ello, el estado se da a sí mismo y a sus autoridades el ordenamiento, como lo hacen también otras colectividades sociales.»

Lo que haya que entender por derecho estatal continúa siendo un misterio. En el mismo capítulo que se titula «El derecho estatal», Ehrlich investiga los efectos del derecho estatal y especialmente las «normas estatales de decisión», e identifica derecho «legal» con derecho del estado a pesar de que haya declarado unas líneas arriba (p. 296) que la mayor parte de las «normas de decisión» establecidas por los códigos constituyen derecho de los juristas y no derecho estatal. Ehrlich afirma entonces (p. 297) que

«en general, se sobreestima el efecto de las normas estatales de decisión... Hace algunos años realicé un estudio que mostraba con qué intensidad se ha manifestado en la vida real el código civil austríaco vigente desde hace cien años.»

¿Es el código civil derecho estatal?

Sólo en la medida en que Ehrlich representa la independencia de derecho y estado frente a la concepción que mantiene que el estado produce el derecho, se puede estar de acuerdo con él, aunque esto sólo es posible partiendo de una posición de la que Ehrlich está ciertamente muy alejado, a saber, que el estado no es capaz en modo alguno de producir derecho, que la idea de un estado productor de derecho es inconcebible. No es éste el lugar adecuado para demostrar lo que acabo de decir. Basta insistir, contra Ehrlich, en que la posibilidad de cualquier forma de derecho estatal acarrea, desde un punto de vista jurídico-normativo, la consecuencia inevitable de un derecho estatal vigente como único -o al menos superior- ordenamiento.

Las unidades sociales que Ehrlich antepone al estado son la «tribu», el «clan», la «comunidad doméstica» (p. 111), la «familia», la «aldea». Ehrlich habla de «tribunales de la aldea», de «tribunales familiares» y no excluiría ciertamente la existencia de tribunales del clan o de la tribu. Presupone estas sociedades, por tanto, como sociedades jurídicas de las que emanan normas jurídicas. Representa ciertamente la opinión -apoyada en la autoridad 
de Gierke- que mantiene que no sólo las normas aplicadas por la 
comunidad jurídica, o por sus órganos, forman parte de las normas jurídicas vigentes; o que los deberes para cuya protección no está llamado a intervenir ningún «poder de la colectividad» también son deberes jurídicos (p. 128). Pero entonces ¿cómo se distinguen estos deberes de los deberes morales? si el derecho es norma de la colectividad, regla de organización, cómo se expresa en estas relaciones la colectividad, la unidad social superior, la organización? ¡En la moral y las costumbres la sociedad no existe como unidad supraindividual!

«La idea de que lo que los señores tienen que conceder a los súbditos es debido en sentido jurídico es inmanente a todos los derechos germánicos de la colectividad. Los deberes exigibles sólo se desarrollan en la medida en que un poder de la colectividad es competente para intervenir y proteger los derechos de los miembros de la colectividad» (p. 128).

¿Pero cómo se puede hablar de un derecho de la colectividad cuando el derecho no tiene ninguna relación con la colectividad como tal? El estado no es otra cosa que la comunidad jurídica entendida en su esencia más profunda, la comunidad jurídica superior, la unidad social que es concebida como un ordenamiento jurídico, a saber, la organización jurídica. Se objetará que es imposible concebir la tribu o el clan como estado, cuando dichos grupos forman parte de unidades sociales superiores, quizá del estado. Supongamos que sea cierto que un clan organizado como sociedad jurídica o cualquier otra clase de grupos constituyan órdenes inferiores vinculados a otros superiores. ¿En qué consiste dicho vínculo? ¿De qué tipo es esta organización a través de la cual varios grupos inferiores están vinculados a una unidad superior? Este orden sólo puede ser precisamente un ordenamiento jurídico que establece los deberes de los individuos, un orden jurídico que es aplicado por determinados órganos -los órganos del grupo superior- y en el que deben insertarse de una forma no contradictoria los órdenes jurídicos de las colectividades inferiores. Si el grupo superior que comprende todas las colectividades inferiores debe constituir realmente una unidad social, es decir, debe ser concebido como una unidad, entonces, los órganos de las colectividades inferiores deben ser concebidos de alguna manera como estando subordinados a los de la colectividad superior, y los diferentes órdenes jurídicos de estas colectividades deben ser representados como válidos y diferenciables sólo dentro de los límites que vienen impuestos a través de la organización del grupo superior que los comprende a todos en una unidad. No es posible 
una construcción de las unidades sociales que no sea normativa. De esta forma, en la construcción normativa -en la que viene dada sólo la unidad ideal de los grupos socialeslos grupos inferiores se convierten en órganos del grupo superior, mientras que los ordenamientos jurídicos de los grupos inferiores -los cuales, manteniéndose dentro de límites locales y objetivos, difieren mucho unos de otros- forman un único sistema de normas, un único ordenamiento jurídico con la organización del grupo superior.

Este último grupo que se edifica sobre los grupos individuales es, en tanto que comunidad jurídica, el estado. ¿Qué otra cosa podría ser el estado?

Ehrlich mantiene que el estado no es una comunidad jurídica:

«Por su origen, el estado es una colectividad militar que sólo de forma indirecta está en relación con la vida jurídica; el estado ha continuado siendo hasta nuestros días y con arreglo a su esencia, una colectividad de carácter marcadamente militar, con la excepción de algunas formaciones modernas de estados en las colonias inglesas, antiguas y actuales, en Norteamérica y en otras partes del mundo» (p. 111).

Ya en estas palabras se aprecia claramente que cuando Ehrlich trata la cuestión de la esencia del estado no se interesa por ese concepto de estado cuya relación con el concepto de derecho se discute en el problema de la relación entre estado y derecho. Ehrlich afirma que el estado es una colectividad militar, para añadir a renglón seguido que sería posible la existencia de estados que no constituyeran tales colectividades. Con independencia de la excepción a la que alude Ehrlich, ¿no es un estado neutralizado -por ejemplo, aquel que en cumplimiento de tratados internacionales, carece de organización militar, de ejércitos, de cuarteles- un estado? ¿Dejarían de ser estados los actuales estados si triunfara el ideal de la paz? Los fines militares podrían caracterizar la mayoría de los estados históricamente conocidos pero no por ello debe determinarse el concepto de estado como una organización militar. De la misma manera, el concepto de estado no es determinado como «organización de explotación» aunque la mayor parte de los estados históricamente conocidos hayan sido organizaciones de explotación. En el concepto de estado deben tener cabida no sólo algunas, o la mayor parte, de las formas históricamente caracterizadas como «estado», sino todo estado posible e imaginable. Es un error querer determinar materialmente el estado -como pretenden Ehrlich y otros tantos- según su contenido, 
según los fines que fueron perseguidos bajo la forma del estado. ¡Pues el estado es una forma de la unidad social, no un contenido! Ehrlich afirma que

«la formación más antigua que históricamente tiene todavía alguna conexión con el actual estado, es la unión de la aristocracia guerrera procedente de varias tribus lingüísticamente próximas que, acompañadas del resto de los hombres libres, se dan un jefe para la guerra, no sólo provisionalmente, sino con vocación de permanencia» (p. 111).

No se entiende por qué, entonces, no la tribu organizada como comunidad jurídica, sino la «aristocracia unida» procedente de varias tribus, debe ser considerada como estado, toda vez que Ehrlich ha caracterizado dicho «estado» como una especie de banda de extorsionadores:

«el estado debe sobre todo poner a disposición del rey, de los jefes de los ejércitos permanentes y de sus seguidores los medios materiales necesarios. Esto sucedía al principio a través de la exigencia de regalos, pasando más tarde a adoptar la forma, en Oriente, de una extorsión» (p. 111).

¿Debe, por tanto, un estado estar formado por varias tribus sólo en la medida que un «grupo de aristócratas» extorsiona al pueblo de dichas tribus? ¿Debe darse con ello la unidad social «estado»? Sólo se puede hablar de estado -siempre que por tal entendamos una unidad social- en el caso de una organización. Las contribuciones de guerra arbitrarias e irregulares de una banda de ladrones como las que representan las «extorsiones» de la «aristocracia guerrera de tribus próximas desde un punto de vista lingüístico», no constituyen todavía un orden estatal. Sí existe, en cambio, una organización militar, es decir, si se presupone la existencia de normas según las cuales se establecen las obligaciones de los individuos, entonces, existe un estado, no debido al contenido especial de estas normas sino porque existe un orden que, con arreglo a su naturaleza, debe ser un orden jurídico. Cuando Ehrlich insiste en que la historia del derecho nos enseña que la legislación no correspondía desde un principio al estado (p. 112), está en lo cierto. ¿Qué jurista medio no sabe que la producción jurídica ha tenido lugar a lo largo de mucho tiempo a través de la «costumbre»? Ehrlich trabaja con un concepto de estado completamente arbitrario cuando mantiene que la administración de justicia o la aplicación del derecho no estaban, originariamente, 
conectadas con el estado. Esto es imposible si se entiende por 
«estado» la comunidad jurídica superior, la organización jurídica. Desde este punto de vista es completamente arbitrario negar el carácter de estado a las comunidades jurídicas independientes más reducidas que se supone más originarias -de momento faltan pruebas históricas sobre la prehistoria del derecho y del estado- y sólo reconocerlo con respecto a colectividades que surgen de la unión de varios de aquellos grupos. Que en la organización jurídica de la gran comunidad los ordenamientos jurídicos de los grupos originariamente independientes sólo puedan mantener sus especialidades dentro de los límites de aquella, en otras palabras, que dichos ordenamientos jurídicos deben formar una unidad con la organización jurídica de la gran comunidad de forma que los órganos jurídicos de los grupos pueden ser concebidos como órganos de la totalidad, es sólo una consecuencia del hecho de que los grupos originariamente independientes se encuentran fusionados unos con otros en una unidad superior.

De nuevo un modo de consideración (Betrachtungsweise) completamente distinto del jurídico, así como un concepto de estado diferente del habitual entra en juego cuando Ehrlich señala que sólo existen tribunales estatales, y con ellos aplicación del derecho, en la medida en que emanan del «poder de mando del señor». Sólo la administración de justicia ejercida por el señor o por sus órganos es de carácter estatal. El modo de designación es indiferente: los jueces elegidos por los municipios también son órganos del estado en la medida en que los municipios son parte constitutiva del estado. Ehrlich opina que la primera jurisdicción estatal fue la del rey. Desde un punto de vista histórico el rey es tanto el juez supremo como el señor más importante. Cuando se concibe el estado de forma fragmentada como una serie de pequeñas comunidades jurídicas que poseen ordenamientos y órganos jurídicos completamente diferentes (tribunales), ¿en qué consiste entonces el lazo que une todos estos grupos y que conforma un estado unitario a partir de los grupos individuales? En todo caso, debe existir un tipo de orden, un orden que sea un límite para los órdenes jurídicos de los grupos individuales. Si este orden no fuera jurídico, ¿cuál sería entonces el límite del estado?

Si toda norma implica una relación con la comunidad jurídica, con el estado, esto no significa que toda relación jurídica deba estar necesariamente unida a una invocación de la autoridad estatal. ¿Debemos todavía insistir en que esta relación con el estado es de naturaleza exclusivamente potencial, que sólo se puede considerar que hay obligación si la violación de ésta tiene como consecuencia de deber-ser la reacción del estado sin que con esto se esté afirmando que toda obligación deba ser violada? ¿Es 
un ácido sólo un ácido cuando se pone en contacto con papel de tornasol? Ehrlich parece forzar dicha conclusión cuando afirma que «hay millones de hombres que participan en innumerables relaciones jurídicas y que son tan felices que no tienen que dirigirse a una autoridad» (p. 130). ¿Se puede realmente imputar a la doctrina dominante, como Ehrlich hace, la opinión de que «la vida humana tiene lugar ante los tribunales» (p. 15), se puede atribuir al «jurista contemporáneo» el que éste «no pueda imaginarse en modo alguno la convivencia sin la coacción» (p. 67)? ¿Cree Ehrlich realmente -como él quiere hacer creer a sus lectores- que la teoría que presenta el derecho en íntima conexión con el estado y que concibe el derecho como «ordenamiento coactivo» estatal, representa la posición sociopsicológica de que los hombres se conducen con arreglo al derecho sólo por miedo de la sanción o ejecución estatal (p. 15)? No se hallaría ciertamente un representante tan necio de la teoría de la coacción, tal y como Ehrlich la concibe. La propia concepción ehrlichiana de la coacción estatal roza lo grotesco:

«En el procedimiento judicial se agota, por tanto, el efecto protector del ordenamiento jurídico coactivo del estado con respecto a la persona del poseedor y de la acción frente a los que están fuera de la sociedad» (p. 57), los «proscritos» (p. 55).

¿No puede, entonces, el ordenamiento jurídico tener -como ordenamiento jurídico coactivo- un «efecto» preventivo? Y aquellos contra los cuales se dirigen la ejecución civil o los medios coactivos jurídico-administrativos, aquellos a los que los jueces imponen penas, ¿son realmente «proscritos», están realmente fuera de la sociedad? Ehrlich caracteriza al Estado como «la colectividad más amplia, el cual comprende incluso a aquéllos ("los proscritos")». Es enigmático que individuos que están comprendidos en el estado, es decir, en una colectividad social, están al mismo tiempo "fuera» de la sociedad. Ehrlich dice que «de esta forma, el estado, como órgano de la sociedad, protege a la sociedad de aquellos que están fuera de la sociedad» (p. 55). Mejor dicho: el estado, que como colectividad comprende incluso a los «proscritos», es un órgano de la sociedad y como tal protege a la sociedad de los que, como parte constitutiva del estado, son un órgano de la sociedad. El estado protege a la sociedad de sí misma o contra una de sus partes constitutivas que sin embargo es algo en lo que no deja de insistir Ehrlich (pp. 122 y 123), lo que no le impide manifestar que el «estado y una gran parte de la sociedad están en oposición» (p. 60). 
Finalmente, cree Ehrlich poder esgrimir un último argumento contra el carácter estatal del derecho (lo que, dicho sea de paso, es lo mismo que decir el carácter jurídico del estado) cuando se refiere al derecho canónico (Kirchenrecht) y afirma que éste

«es derecho con independencia de cómo se comporte el estado en relación con él, dado que éste es el ordenamiento jurídico de la iglesia» (p. 130).

¿No se da cuenta Ehrlich de que esta frase viene a decir que el derecho canónico es derecho porque es derecho? Precisamente porque Ehrlich, en la determinación del concepto de derecho, renuncia a la relación con el estado como la sociedad específicamente jurídica, su concepto de derecho no debe -si dejamos a parte el intento, que apenas se puede tomar en serio, de caracterizar las diferentes normas a través de las diferentes respuestas emocionales que produce la violación de aquéllas- llevar a ninguna parte ni coincidir con el de una norma o regla social. Desde un punto de vista sociológico, la posición de Ehrlich -en la medida en que se determina de una forma clara y no contradictoria- se desvanece en una identificación del derecho y de la sociedad, mientras que una dirección basada en la clara delimitación entre derecho y otras normas sociales conduce, como una de sus consecuencias más evidente, a la identificación del derecho y del estado.

\section{V}

Los dos capítulos finales del trabajo de Ehrlich tratan de los «métodos de la sociología del derecho». En ellos resume Ehrlich su concepción sobre la esencia de la nueva ciencia al tiempo que alcanza el punto culminante de obscuridad y contradicción interna. En estos capítulos finales vuelve a subrayar Ehrlich la oposición entre una «ciencia» del derecho «teórica», la sociología del derecho, y una jurisprudencia «práctica». Ya tuvimos la ocasión de señalar en la introducción, que Ehrlich desarrolla dicha oposición -cuya aplicación correcta habría sido de gran importancia- de una forma muy obscura. Al final resulta que el principio metodológico y fundante ha perdido todo significado posible en la obra de Ehrlich. Después de que haya insistido con anterioridad (p. 314) en que la «ciencia del derecho sociológica, como toda ciencia, tiene que limitarse a registrar los hechos, no a valorarlos», y que, por tanto, no tiene que decir lo que debe ser, y especialmente no tiene que decir lo que debe ser con arreglo al derecho, a lo que se 
tiene derecho o a lo que se está obligado, o lo que es lícito o ¡lícito (en el sentido de un juicio de valor), Ehrlich añade que «también la sociología del derecho debe ser una ciencia de la observación (Beobachitungswissenschaft)». Dice del sociólogo del derecho que éste tiene que «reunir hechos para conocerlos y explicarlos» (p. 382). En particular, el enunciado jurídico es considerado meramente como hecho, esto es, desde su origen y sus efectos y no desde su aplicación práctica y su interpretación; lo que expresado de una manera más precisa significa: explicar los enunciados jurídicos, entendidos como hechos socio-psicológicos, a partir de su emergencia y sus efectos, entender el derecho como fuerza (Macht), no considerar las normas jurídicas desde su validez de deber-ser (Sollgeltung), no concebir el derecho como norma. Esta correcta determinación de una sociología del derecho puramente explicativa contrasta con lo que Ehrlich afirma de la «jurisprudencia práctica». En efecto, para Ehrlich, la «jurisprudencia práctica» debe conocer, a diferencia de la sociología del derecho teórica -la única ciencia del derecho según Ehrlich-, lo que debe ser con arreglo al derecho; no se dedica a explicar o constatar hechos sino a valorarlos. Pues bien, esta «jurisprudencia práctica», que para Ehrlich es «acientífica» por ser normativa, debe «ofrecer una imagen de la sociedad a la que las normas (que dicha jurisprudencia expone) deben aplicarse» (p. 384). ¿Cómo es posible dar una imagen de la sociedad con medios práctico-jurídicos? ¿No es la exposición de las relaciones sociales existentes, metodológicamente, una tarea de la sociología en oposición a la jurisprudencia «práctica»? La oposición entre «teórico» y «práctico» que introduce Ehrlich a propósito de las relaciones entre la sociología del derecho y la jurisprudencia queda completamente puesta en entredicho cuando aquél afirma hacia el final de su obra que la jurisprudencia es también una «ciencia», es decir, en el sentido que Ehrlich da a esta expresión, que se ocupa de describir y de explicar hechos -esto es, el ser- causalmente, no de valorarlos.

«La intuición viva de las relaciones humanas de tipo jurídico, la generalización de los resultados de dicha intuición y de las normas de decisión correspondientes, esto es lo científico en la jurisprudencia. Hasta cierto punto, la jurisprudencia es una morfología de las formas jurídicas de la vida social»,

o como reza el encabezamiento de la página: «una morfología de la sociedad» (p. 385). Debemos suponer que se trata aquí de hechos-de-ser (Seinstatsachen), pues a éstos debe seguir un conocimiento en sentido «científico»; ¿dónde está entonces la oposición 
a la sociología del derecho? «También la denostada parte general (de la jurisprudencia práctica) entraña ciencia». ¿Ciencia en el sentido de Ehrlich? La confusión completa de los principios metodológicos de una disciplina práctica y teórica se consuma en los últimos y significativos resultados de la sociología del derecho de Ehrlich: la investigación del derecho vivo.

Partiendo de la base de que nuestra ciencia del derecho actual sólo se ocupa de los enunciados jurídicos, «el estado actual de nuestro derecho es en gran parte desconocido» (p. 395). El código civil austríaco dispone, salvo pacto matrimonial en contrario, que el régimen económico-matrimonial es la comunidad de gananciales (eheliche Gütergemeinschaft). El campesinado austríaco-alemán vive efectivamente bajo la comunidad de gananciales aunque ésta venga regulada frecuentemente -a través de pactos- por una de las derogaciones previstas en el código civil. La doctrina no nos informa acerca del contenido efectivo de los pactos matrimoniales en el campesinado de la misma forma que no lo hace con respecto al contrato de arrendamiento o al testamento (pp. 396, 397), los cuales adoptan regularmente, en ciertos grupos sociales, un contenido que es dejado a la disposición de las partes por el código. Desgraciadamente Ehrlich no ofrece ningún material en apoyo de una afirmación que es muy interesante desde un punto de vista sociológico. La doctrina tampoco sabe nada de la "constitución agraria» efectiva o del ordenamiento familiar efectivo que no se corresponde en ningún país europeo con las normas del derecho positivo (des gesetzten Rechtes) (p. 397). Es necesario detenerse aquí. El derecho es la forma bajo la cual tiene lugar o debe tener lugar la vida económica y política. La ciencia del derecho debe expresar algo sobre las formas pero no lo puede hacer (en todo caso con los medios específicos de los que dispone y dentro de los límites de su objeto) con respecto al contenido que debe desarrollarse bajo la forma del derecho (si la ciencia del derecho es concebida como una ciencia normativa) o que se desarrolla efectivamente bajo dicha forma (cuando se la concibe sociológicamente). Ehrlich simplemente identifica derecho y sociedad, es decir que caracteriza como derecho no sólo a la forma sino también al contenido de los fenómenos sociales, cuando exige de la jurisprudencia que le ofrezca una información acerca de las relaciones regulares de naturaleza económica y política que forman el contenido de las formas jurídicas. La jurisprudencia también debería ser entonces economía nacional, historia económica, si tuviera que ofrecernos información sobre la constitución agraria de un país o sobre las relaciones económicas efectivas entre los cónyuges, entre los arrendadores y los arrendatarios, etc. ¡Una 
eliminación de los límites, como hace Ehrlich, entre derecho y economía, entre derecho y sociedad y, por tanto, entre la jurisprudencia y el resto de las ciencias sociales, no tiene precedente! ¿Cuál es el significado de cada regla que expresa algo sobre el contenido de ciertos negocios jurídicos o de ciertas relaciones jurídicas? Según Ehrlich estas reglas son el «derecho vivo». Su esencia se manifiesta en la siguiente frase: «También aquí cumple defectuosamente su tarea la ciencia entendida como doctrina (Lehre) del derecho (Ehrlich se refiere a la jurisprudencia dominante) cuando se limita a exponer lo que la ley prescribe sin referirse también a lo que sucede en realidad» (p. 398). Según Ehrlich la tarea de investigar y exponer el «derecho vivo», esto es, las reglas del acaecer efectivo, no es sólo tarea de una sociología no valorativa que se limita a constatar y explicar hechos, sino también de una jurisprudencia práctica. Se reprocha a la jurisprudencia dominante el que no haga esto. Pero ¿cuál es la razón suficiente para caracterizar como «derecho» las reglas del acaecer efectivo obtenidas a partir de la observación del ser (Beobachtung des Seins), lo que no puede significar otra cosa que cuando algo sucede regularmente también tiene que suceder porque así lo ordena el derecho? Una sociología, en tanto que ciencia del ser (Seinswissenschaft) -en sentido ehrlichiano- no está autorizada a extraer esta conclusión; una sociología así entendida no podría nunca conocer ni mostrar normas jurídicas (como normas de deber-ser). Para una jurisprudencia práctica, la cuestión de saber si un acaecer efectivo también debe acaecer no ha de responderse desde esta posición. ¿Se puede entonces decir de todo lo que sucede regularmente que también debe suceder o incluso que debe suceder porque así lo establece el derecho? Eso y no otra cosa significa la afirmación de que el derecho vivo existe. ¿Y qué ocurre si este acaecer efectivo -según la frecuente hipóstasis de Ehrlich- está en contradicción con normas que el jurista práctico debe suponer también, por cualquier razón, como normas jurídicas válidas? ¿No significa esto pedir a la jurisprudencia «práctica»-«práctica» en tanto que ésta se ocupa del conocimiento del deber-ser jurídico- que renuncie a la condición fundamental de todo conocimiento al exigirle que considere como verdaderos dos enunciados (enunciados jurídicos) contradictorios, a saber la norma presupuesta como válida y la norma del derecho vivo que las contradice, esto es, que renuncie a concebir el ordenamiento jurídico como un todo coherente y libre de contradicción, en otras palabras, que renuncie a concebir el derecho en general?

El carácter completamente ambiguo de las reglas del acaecer efectivo que Ehrlich denomina el «derecho» vivo aparece claramente 
en el siguiente ejemplo ofrecido por el mismo Ehrlich. Ehrlich señala que ha investigado los efectos del código civil en Bukowina. Desgraciadamente Ehrlich no nos da a conocer en su obra estas eminentes investigaciones jurídico-sociológicas. Esto habría sido importante porque de esta forma se hubiera suministrado finalmente el material y el método para la solución de un problema jurídico-sociológico realmente concreto. Ehrlich nos habla especialmente de la ineficacia de las disposiciones del derecho de familia del código civil austríaco. Con arreglo a las disposiciones de este código civil, el menor (Hauskind) puede poseer y disponer libremente de su propio patrimonio. La adquisición es en beneficio del menor y no de los padres. En Bukowina -informa Ehrlich-, territorio «que pertenece a Austria y donde el código civil está en vigor como en otras partes de Austria», es el campesino rumano el que dispone de hecho del patrimonio de su hijo: «si el menor trabaja, todos los meses su padre o su madre van a ver al patrón para cobrar el salario y llevárselo a casa» (p. 298). Es una lástima que de estas indicaciones no se desprenda en qué número de casos Ehrlich ha constatado lo que acaba de referir. Es de suponer que también podría constatarse otros casos en los que el menor dispone libremente de su ganancia. Pero ¿qué indican los hechos observados por Ehrlich? ¿Que en Bukowina el menor no tiene derecho a disponer de su ganancia? ¿Responderá como abogado o como juez el profesor Ehrlich cuando diga: estás obligado jurídicamente a permitir que tus padres dispongan de tu ganancia sin tu consentimiento? No dudo de que el profesor Ehrlich, como juez o como abogado, atribuirá al menor los derechos que le correspondan con arreglo al código civil, ¡incluso en Bukowina! Desde luego, si el menor está de acuerdo, o como dice Ehrlich, si «consiente tácitamente» (sich ruhig gefallen lä $\beta$ t) en que su padre disponga de su ganancia, entonces el estado de hecho descrito por Ehrlich no es incompatible de ninguna forma con el código civil. La ley otorga al menor underecho; si el menor no hace uso de él, es asunto suyo. El menor puede transmitir su derecho o su ganancia en un negocio concreto a su padre; también puede, con arreglo al derecho, dárselos en donación, así como cederle su salario o dejar que el derecho se pierda. En todos estos casos, el menor no actúa contra la ley. Quizá el hecho observado por Ehrlich, en la medida en que constata su regularidad en el seno de un grupo social, es una costumbre, pero no desde luego una costumbre que contradice la ley, como Ehrlich cree (p. 299). Caso distinto sería si el código civil estableciera una obligación jurídica a cargo del menor. En ese caso, si las obligaciones establecidas por la ley no fueran observadas efectivamente, serían violadas regularmente por todo 
el grupo. La norma jurídica en vigor no tendría ningún efecto con respecto a dicho grupo. Es seguro que la tarea de una sociología del derecho sería investigar el efecto de las normas jurídicas. Ahora bien, ¿qué nos puede decir una sociología del derecho que sólo toma en consideración y explica lo existente (das Seiende), una sociología que, como el propio Ehrlich admite, «debe sólo registrar y no valorar los hechos» (p. 314), qué nos puede decir acerca de si lo que sucede efectivamente, también debe suceder, por mandato de la moral o del derecho? ¿Qué nos dice esa sociología de lo que es lícito?

Lo que Ehrlich señala como «derecho vivo» no es una categoría jurídica en la medida en que como «derecho vivo» se entienda el contenido regular de las diferentes relaciones jurídicas, sino un interesante objeto para la descripción de la economía y para la explicación de la sociedad. El conocimiento de estos hechos puede tener un valor para el legislador, como en general lo tiene el conocimiento de los hechos sociales. Pero para una sociología del derecho que se diferencie de la descripción de la economía y de una teoría general de la sociedad, aquel objeto de derecho no debe estar dado como algo que va de suyo. En la medida en que esa disciplina se delimita y es operativa, su problema radica en el origen $\mathrm{y}$ en el efecto de las normas jurídicas, entendiendo por tales los hechos socio-psíquicos. Para una sociología del derecho, sólo en la medida en que en relación con la formación del contenido de las relaciones jurídicas se tratara del efecto de las normas jurídicas, entraría en consideración este contenido del derecho.

Parece, por tanto, que una sociología del derecho como disciplina independiente se enfrentaría a graves dificultades. Sólo es posible una sociología del derecho en estrecha relación con una sociología de la moral y de las costumbres, o dicho de otra manera, en relación con una sociología del resto de las normas sociales. El comportamiento efectivo del hombre en la medida que un enfoque jurídico-formal considera regular dicho comportamiento no se manifiesta como estando motivado exclusivamente por las normas jurídicas, sino también por normas de otro tipo. Y puesto que el cometido de una sociología también es investigar las causas de la ineficacia del derecho, es decir, los motivos de los comportamientos antijurídicos, dicha sociología debe desvelar todo el mecanismo del acaecer social para resolver sus problemas. La sociología del derecho, en sentido estricto, no es una ciencia propia (keine eigene Wissenschaft); se trata de una parte extraída de un modo completamente arbitrario -desde el punto de vista del conocimiento sociológico- de una ciencia general que considera y explica la vida social. Pues la delimitación del dominio de 
esta sociología del derecho debe llevarse a cabo a través de un concepto cuya determinación viene dada a partir de un punto de vista completamente diferente del de una sociología explicativa, a saber a través del concepto normativo de derecho. La sociología del derecho no puede determinar lo que es derecho o al origen y efecto de qué normas debe limitarse dicha forma de conocimiento; la sociología del derecho debe presuponer el concepto normativo de derecho. Ahora bien, dado que es el concepto normativo de derecho el que delimita los problemas de la sociología del derecho, los límites de ésta deben aparecer como arbitrarios desde el punto de vista de aquella ciencia de la que la sociología del derecho es una rama, a saber la sociología. Que las normas cuyo efecto determina el comportamiento social sean normas jurídicas o normas de la moral poco le importa al punto de vista sociológico. Para el aspecto puramente sociológico no habrá ninguna diferencia esencial entre estas normas, es decir, entre los hechos psíquicos, entre las representaciones que estas normas tienen por contenido. Sólo la idea errónea de que la sociología tiene el mismo objeto, en general, que la jurisprudencia normativa, conduce a la idea de una sociología del derecho autónoma. La norma jurídica, ese objeto específico de la ciencia del derecho, no viene dada en modo alguno a una sociología orientada hacia el ser (auf das Sein gerichtete Soziologie). ¡La representación o la percepción de la norma jurídica como deber-ser jurídico es algo completamente distinto! Un concepto sociológico de derecho, del que recientemente tanto Ehrlich como otros hablan, es tan inimaginable como un concepto matemático de un proceso biológico o un concepto moral de la gravedad. El intento ehrlichiano muestra claramente que una sociología del derecho tiende inevitablemente a convertirse en una sociología de la sociedad dado que el concepto de derecho no puede delimitarse sociológicamente.

El intento de Ehrlich de fundamentar la sociología del derecho se debe considerar como completamente frustrado, sobre todo como consecuencia de una falta de claridad en el planteamiento de los problemas y de una ausencia de método preciso. Lo que se desprende de sus explicaciones caóticas y contradictorias no es ciertamente otra cosa que el lugar común aceptado -que Ehrlich enfatiza en el prólogo y que representa el sentido de su obra- a saber el enunciado que afirma que lo esencial del desarrollo jurídico radica en la sociedad. ¡Naturalmente! ¡Desde luego que el desarrollo jurídico completo se realiza como proceso social en la sociedad! Sólo que las pretensiones que Ehrlich atribuye a la ciencia fundada por él deben ser en parte rechazadas cuando Ehrlich afirma que en ese enunciado está «contenido el sentido de 
toda fundamentación de una sociología del derecho», puesto que eso sería tan elocuente como aprehender el sentido de toda biología a través del enunciado que dijera que el desarrollo de los organismos radica en la naturaleza.

(Traducción de Adolfo Barberá) 